\title{
CONFLICTOS CONTRACTUALES DEL EMPRESARIO CON LA ADMINISTRACIÓN PÚBLICA EN SANTANDER: CARACTERIZACIÓN SOLUCIONES JUDICIALES 2008 - 2009
}

\author{
Angélica María Reyes Sánchez \\ Magister en Hermenéutica Jurídica y Derecho de la Universidad Industrial de Santander - UIS; Estudios \\ de Maestría en Derecho con Énfasis en Derecho Empresarial y Contractual de la Universidad Santo Tomás \\ Bucaramanga. Abogada, Universidad Santo Tomás Bucaramanga; Docente Investigadora, Facultad de Derecho de \\ la Universidad Santo Tomás Bucaramanga. (Colombia). \\ Correo electrónico: angelik1024@gmail.com
}

\begin{abstract}
Resumen
El análisis realizado a las decisiones judiciales que proferidas en los años 2008 y 2009, dieron solución a los conflictos contractuales del empresario con la administración pública, pretende mostrar su caracterización, a partir de un conjunto de categorías previamente establecidas, para efectos del análisis, en desarrollo de dos avances anteriores del proyecto de investigación: uno contentivo de la revisión teórica sobre el sistema de fuentes y los métodos de interpretación y el otro en torno a la descripción de las principales características de la relación jurídica empresario - administración pública. Concluidas estas líneas, se encontrará que, durante el periodo analizado, los conflictos contractuales en Santander giraron en torno a: 1. El incumplimiento del contrato, 2. Las diferencias surgidas al momento de la liquidación del contrato, 3 . La posible nulidad de actos administrativos precontractuales o contractuales, 4 . La ocurrencia de hechos imprevisibles y el rompimiento del equilibrio económico y 5 . La existencia del negocio jurídico. Además, que la solución judicial dada por el TAS a dichos conflictos se soporta en una labor interpretativa que, pese a los intentos por atender a ese modelo complejo de fuentes y métodos de interpretación propios del ordenamiento jurídico colombiano, hace mayor acento en la ley y la jurisprudencia como fuentes del derecho, involucra de manera progresiva al contrato, la Constitución y otras fuentes, junto a las cuales se encuentran los métodos de interpretación que corresponden a dicha tendencia y que pueden variar de acuerdo a la naturaleza del conflicto.

Palabras Clave: Conflictos Contractuales, Solución Judicial, Labor Interpretativa, Empresario, Administración Pública.
\end{abstract}

\begin{abstract}
The results of the analysis brought upon the Administrative Tribunal of Santander's judicial decisions emitted during the years 2008 and 2009, giving answer to the contractual conflicts between the entrepreneur and the public administration, and the characterization of its interpretative task, as the next step towards two briefings of the research project: 1.Theorical revision of the sources and methods of interpretation of the law; and 2. Description of the main characteristics of the entrepreneur-public administration juridical relationship. Moreover, we will find that, during the aforementioned period, the contractual conflicts in Santander were mainly on the subject of: 1. Breach of Contract; 2 . Receivership; 3. Nullity of Administrative Acts; 4. Occurrence of an unpredictable event and breach of the economic equilibrium of the contract; and 5. Existence (or not) of the contract. Furthermore, we will encounter that the solution brought by the Administrative Tribunal of Santander to such conflicts are supported by a interpretative task that focuses mainly on the law and the jurisprudence as sources of the law, progressively involving the contract, the National Constitution and other sources; with which we may include the methods of interpretation of the law corresponding to such tendency which may vary according to the nature of the conflict.
\end{abstract}

Key Words: Contractual Discrepancies, Judicial Resolve, Interpretative task, entrepreneur, public administration.

\section{Résumé}

L'analyse réalisée aux décisions judiciaires que proférées dans les années 2008 et 2009, ils ont donné la solution aux conflits contractuels de l'entrepreneur avec l'administration publique, essaie de montrer sa caractérisation, à partir de l'ensemble de catégories au préalable établies, pour des effets de l'analyse, à un développement de deux progressions antérieures du projet de recherche : l'un contentif de la révision théorique sur le système de fontaines et les méthodes d'interprétation et l'autre autour de la description des caractéristiques principales de la relation juridique un entrepreneur - une administration publique. Finies ces lignes, on trouvera que, durant la période analysée, les conflits contractuels au Santander ont tourné autour de : 1. L'inaccomplissement du contrat, 2. Les différences surgies au moment de la liquidation du contrat, 3 . La nullité possible d'actes administratifs précontractuels ou contractuels, 4 . La circonstance de faits imprévisibles et la rupture de l'équilibre économique et de 5. L'existence de l'affaire juridique. De plus, que la solution judiciaire donnée par le TAS aux dits conflits se supporte dans un travail interprétatif que, malgré les tentatives pour faire attention à ce modèle complexe de fontaines et de propres méthodes d'interprétation de l'ordonnance juridique colombienne, il fait un plus grand accent dans la loi et la jurisprudence comme fontaines du droit, implique d'une manière progressive au contrat, la Constitution et d'autres fontaines, près desquelles se trouvent les méthodes d'interprétation qui communiquent à la dite tendance et qui peuvent varier conformément à la nature du conflit.

Mots-clés: Des conflits Contractuels, une Solution Judiciaire, un Travail Interprétatif, Entrepreneur, Administration Publique. 

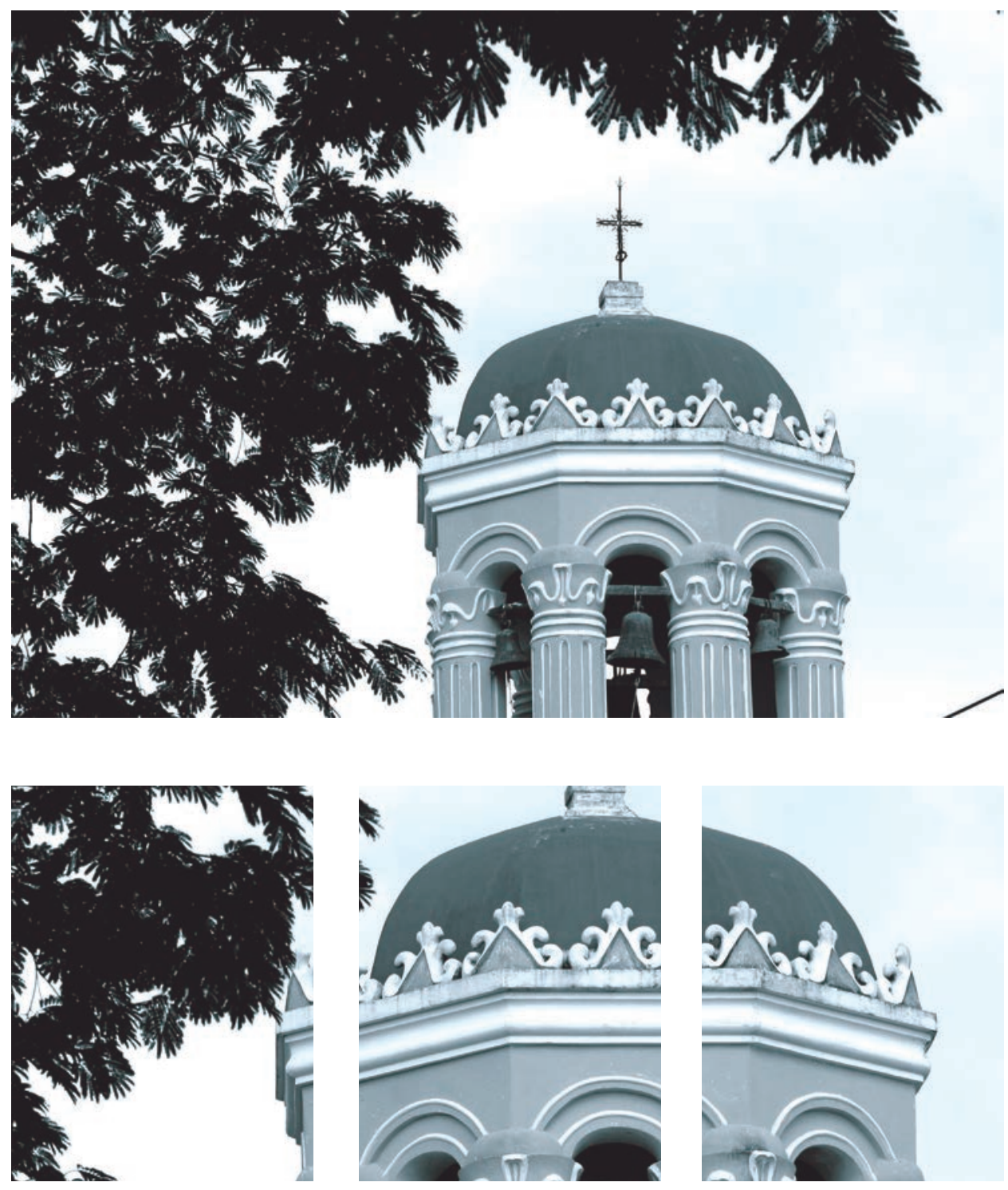

Iglesia de Santa Bárbara - Mompóx - Colombia

Martín Emilio Hernández Manrique 


\section{CONFLICTOS CONTRACTUALES DEL EMPRESARIO CON LA ADMINISTRACIÓN PÚBLICA EN SANTANDER: CARACTERIZACIÓN SOLUCIONES JUDICIALES 2008 - 2009*}

Angélica María Reyes Sánchez

\section{INTRODUCCIÓN}

La importancia del estudio realizado y de las conclusiones que puedan obtenerse a partir del mismo encuentran soporte en la naturaleza de la relación en conflicto, esto es, la relación contractual del empresario con la Administración Pública, toda vez que las finalidades que persigue la actividad contractual de la administración -cumplimiento de los fines impuestos al Estado por la Constitución Política - y el papel del empresario dentro de dicha actividad -colaborar a la administración en el cumplimiento de los fines estatales- justifican la existencia de la misma bajo un régimen jurídico determinado que, en todo caso, debe contemplar parámetros de solución a los conflictos que surgen de su dinámica natural.

En este sentido dentro de una relación necesaria, como la contractual con la administración pública, caracterizada por circunstancias y conflictos de índole económico -por la contribución al desarrollo económico y social del país-, la solución judicial que se formule a sus conflictos, es un elemento que debe considerar el empresario al momento de involucrarse en ella, pues el desarrollo fluido o no de la misma dependerá de esos supuestos. Esta circunstancia evidencia, una vez más,

\footnotetext{
* El artículo es producto de la Investigación: Conflictos contractuales del empresario con la Administración Pública: Estudio de Caso Judicial. - Quinta Convocatoria Interna Universidad Santo Tomás Bucaramanga 2010, adelantada por la autora. Grupo de Investigación Neoconstitucionalismo y Derecho, Línea de Investigación, Organización y Actividad Empresarial, Facultad de Derecho, Universidad Santo Tomás Bucaramanga-Colombia.
} 
la importancia del estudio adelantado del cual se describen algunos avances que constituyen aportes a la actividad del juez, desde la academia.

Es imposible negar que el cumplimiento de los fines del Estado exija el despliegue de la actividad contractual de la administración pública y la colaboración del empresario en la misma, por lo que esta relación jurídica se convierte en una necesidad para la vida empresarial por las contribuciones al desarrollo económico y social del país.

En desarrollo de esta actividad el Estado se involucra en el mundo de la libre competencia, la iniciativa privada y el mercado de bienes y servicios, sin perder de vista el interés público que persigue", pues en todo caso "el ejercicio del poder público, (...) lo sigue colocando en posición privilegiada, ingresando de esta manera en la relación contractual no como parte, sino como titular de la función pública que se concreta en la expedición de actos de poder (Mier, 2004, 69).

Por su parte, el empresario colabora con la Administración en el cumplimiento de los fines en desarrollo de su actividad económica y, además, persigue la utilidad correspondiente por la retribución a los servicios prestados, sin embargo, en atención a la nueva fórmula de Estado Social de Derecho, y a la vinculación ${ }^{2}$ de los particulares con el desarrollo del país, extiende a los mismos el ejercicio de la función pública en casos expresamente consagrados como tal, entre ellos "la contratación o participación de los particulares en la gestión misma o realización de las funciones estatales" (Montes, 2002, 139).

El contrato que surge entre empresario y administración no resulta ajeno a las vicisitudes que surgen en la celebración, ejecución o terminación de todo acuerdo de voluntad, conflictos que en todo caso deben encontrar solución pronta e idónea para evitar que el cumplimiento de su objeto se paralice y, en consecuencia, la prestación del servicio se vea afectada. Para ello, el ordenamiento jurídico colombiano dispone

1 La administración pública, como parte en la relación contractual, "busca el cumplimiento de los fines estatales, la continua y eficiente prestación de los servicios públicos y la efectividad de los derechos e intereses de los administrados que colaboran con ellas en la consecución de dichos fines" (Ley 80, 1993. Art. 3). Por lo que deberá dirigir su acción para que el contrato se desarrolle en las mejores condiciones, imponiendo ciertas cargas que han sido consagradas en el Art. 4 de la Ley 80 de 1993.

2 Circunstancias que "indican claramente que el querer constitucional es una amplia participación de los particulares en toda las expresiones de la vida nacional” (Montes, 2002, 139), en virtud del principio de solidaridad y el deber que se le impone al particular de contribuir con el desarrollo del país y el bienestar de la población, contando con los medios para apoyar con la prestación de los servicios, el desarrollo de obras y el suministro de bienes que el Estado requiere para cumplir con sus fines y deberes, teniendo en cuenta que al celebrar y ejecutar un contrato estatal colaboran con las entidades estatales en el logro de sus fines y cumplen una función social que, como tal, implica obligaciones (Ley 80, 1993. Art 3), sin que ello involucre carencia de derechos, pues la Ley 80 de 1993 ha consagrado en su artículo 5 los deberes y derechos de los contratistas, los cuales deberán ser respetados por parte de la administración. 
dos vías de solución, ante la falta de acuerdo directo ${ }^{3}$, que en ejercicio de la función jurisdiccional consagrada en el Artículo $116^{4}$ de la Constitución Política de Colombia se encuentra en cabeza, entre otros y para efectos de los conflictos objeto de estudio, del Consejo de Estado, los Tribunales y los jueces y los particulares en condición de árbitros habilitados por las partes para proferir fallos en derecho.

A pesar de las dos vías: arbitral y judicial, ésta aún es la más usual y concurrida -especialmente por el empresario- pese a los inconvenientes, costos y resultados que trae para sus intereses; por lo menos, es la situación que se observa en el Tribunal Administrativo de Santander (TAS), , toda vez que de los 16 fallos proferidos en primera instancia en acciones contractuales durante el periodo 2008 - 2009, el $81.25 \% 5$ fueron adversos a las pretensiones del demandante que en todo caso fue el empresario y el $18.75 \%{ }^{6}$ restante favorable a las pretensiones, sin embargo, en estos casos el demandante era la Administración Pública.

La situación anterior motiva el desarrollo de un proyecto de investigación que responda ¿Cuáles son las razones que sirven de fundamento a las decisiones judiciales de primera instancia proferidas por el Tribunal Administrativo de Santander en el periodo 2008 - 2009 en acciones contractuales sometidas a su conocimiento? Para ello es necesaria la revisión de las decisiones judiciales dadas por el TAS a los conflictos contractuales sometidos a su conocimiento, se espera como resultado hacer una caracterización de la solución judicial

\section{METODOLOGÍA}

Atendido al carácter descriptivo del proyecto de investigación que soporta el avance referido en estas líneas, el análisis de las decisiones judiciales objeto de estudio se hizo a partir del método inductivo, en virtud del cual se revisó de manera individualizada cada fallo en aras de identificar los elementos generales de identificación, seguidos de aspectos relacionados con el conflicto sometido a conocimiento para finalmente precisar la labor interpretativa del TAS a partir de un conjunto de categorías previamente definidas. De este análisis individual puede obtenerse como consolidado la caracterización de la solución judicial que nos hemos

3 A pesar que, en palabras de Patricia Mier Barrios, la ley prohíja los mecanismos de arreglo directo, queriendo con ello no sólo afianzar la responsabilidad de los servidores públicos en el manejo autónomo de la actividad contractual, sino evitar, en caso de conflictos, el desgaste administrativo y por sobre todo de recursos públicos que la mayoría de las veces alcanzan sumas inusitadas por el solo transcurso del tiempo, sanción pecuniaria que con creces sobrepasa los montos de las sumas debidas y nunca reconocidas oportunamente_(Mier, 2004, 72).

4 Modificado por el Artículo 1 del Acto Legislativo 3 de 2002 Artículo 116.

5 En total 14 Sentencias adversas al demandante de las 16 que en primera instancia profirió el TAS durante el periodo $2008-2009$

6 En total 3 Sentencias favorables al demandante de las 18 que en primera instancia profirió el TAS durante el periodo $2008-2009$. 
propuesto, para luego contrastar con los avances teóricos previos y dar terminación a la investigación inicial.

La población objeto de estudio está integrada por los 16 fallos de primera instancia proferidos por el TAS en el periodo 2008 - 2009 en acciones contractuales y que se relacionan en el Cuadro No. 1.

Cuadro No. 1. Sentencias de primera instancia proferidas por el TAS en acciones contractuales durante el periodo 2008 - 2009

\begin{tabular}{|c|c|c|c|c|c|c|}
\hline No. & RAD. & $\begin{array}{l}\text { MG. } \\
\text { Ponente }\end{array}$ & DEMANDANTE & DEMANDADO & $\begin{array}{l}\text { TEMA DE LAS } \\
\text { PRETENSIONES }\end{array}$ & SENTENCIA \\
\hline 1 & $\begin{array}{c}2002- \\
1576\end{array}$ & Julio Ramos & $\begin{array}{l}\text { Fábrica de carretillas } \\
\text { León - Abdón León }\end{array}$ & $\begin{array}{l}\text { Nación - Instituto } \\
\text { Nacional } \\
\text { Penitenciario y } \\
\text { Carcelario - Cárcel } \\
\text { Distrito Judicial } \\
\text { Bucaramanga }\end{array}$ & $\begin{array}{l}\text { Incumplimiento } \\
\text { contrato de } \\
\text { arrendamiento }\end{array}$ & $27 / 08 / 2009$ \\
\hline 2 & $\begin{array}{c}2000- \\
1514\end{array}$ & $\begin{array}{l}\text { Milcíades } \\
\text { Rodríguez }\end{array}$ & $\begin{array}{c}\text { Corporación para la } \\
\text { investigación y desarrollo } \\
\text { en asfaltos en el sector } \\
\text { transporte e industrial } \\
\text { "Corasfaltos" }\end{array}$ & $\begin{array}{l}\text { Departamento de } \\
\text { Santander }\end{array}$ & $\begin{array}{c}\text { Liquidación } \\
\text { contrato, } \\
\text { incumplimiento del } \\
\text { contrato }\end{array}$ & $31 / 07 / 2008$ \\
\hline 3 & $\begin{array}{c}1999- \\
846\end{array}$ & $\begin{array}{l}\text { Milciades } \\
\text { Rodríguez }\end{array}$ & $\begin{array}{c}\text { Compañía agrícola de } \\
\text { seguros }\end{array}$ & Coormagdalena & $\begin{array}{c}\text { Nulidad autos } \\
\text { administrativos, } \\
\text { No afectación de la } \\
\text { póliza }\end{array}$ & $22 / 01 / 2009$ \\
\hline 4 & $\begin{array}{c}1998- \\
810\end{array}$ & $\begin{array}{l}\text { Milcíades } \\
\text { Rodríguez }\end{array}$ & Manuel Ojeda Villamizar & $\begin{array}{c}\text { Empresa } \\
\text { Colombiana de } \\
\text { Petróleos - Ecopetrol }\end{array}$ & $\begin{array}{l}\text { Nulidad liquidación } \\
\text { unilateral } \\
\text { del contrato, } \\
\text { Rompimiento } \\
\text { equilibrio } \\
\text { contractual, } \\
\text { Incumplimiento del } \\
\text { contrato }\end{array}$ & $21 / 08 / 2009$ \\
\hline 5 & $\begin{array}{c}1999- \\
123\end{array}$ & $\begin{array}{l}\text { Francy del } \\
\text { Pilar Pinilla }\end{array}$ & $\begin{array}{c}\text { Consorcio Ríos } \\
\text { Construcciones Limitada }\end{array}$ & $\begin{array}{c}\text { Empresa } \\
\text { Colombiana de } \\
\text { Petróleos - Ecopetrol }\end{array}$ & $\begin{array}{c}\text { Ocurrencia } \\
\text { de hechos } \\
\text { imprevisibles, } \\
\text { incumplimiento } \\
\text { contrato }\end{array}$ & $29 / 08 / 2008$ \\
\hline 6 & $\begin{array}{c}1998- \\
1623\end{array}$ & $\begin{array}{l}\text { Francy del } \\
\text { Pilar Pinilla }\end{array}$ & Javier Pereira Areiza & $\begin{array}{l}\text { Municipio de } \\
\text { Bucaramanga }\end{array}$ & $\begin{array}{l}\text { Incumplimiento } \\
\text { contrato }\end{array}$ & 28/05/2009 \\
\hline 7 & $\begin{array}{c}2004- \\
382\end{array}$ & $\begin{array}{l}\text { Francy del } \\
\text { Pilar Pinilla }\end{array}$ & $\begin{array}{l}\text { Cooperativa multiactiva } \\
\text { de trabajadores y } \\
\text { empleados de las } \\
\text { empresas varias de } \\
\text { Medellín E.S. P. } \\
\text { Coomultreevv }\end{array}$ & $\begin{array}{l}\text { Municipio de } \\
\text { Barrancabermeja }\end{array}$ & $\begin{array}{l}\text { Nulidad resolución } \\
\text { contrato }\end{array}$ & 09/07/2009 \\
\hline
\end{tabular}




\begin{tabular}{|c|c|c|c|c|c|c|}
\hline 8 & $\begin{array}{c}2000- \\
1815\end{array}$ & $\begin{array}{l}\text { Francy del } \\
\text { Pilar Pinilla }\end{array}$ & $\begin{array}{c}\text { Estudios Técnicos y } \\
\text { Asesorías S. A. ETA S. A. }\end{array}$ & $\begin{array}{l}\text { Departamento de } \\
\text { Santander }\end{array}$ & $\begin{array}{l}\text { Incumplimiento de } \\
\text { contrato, silencio } \\
\text { administrativo } \\
\text { positivo, Nulidad } \\
\text { acto administrativo, } \\
\text { perjuicios, }\end{array}$ & $10 / 12 / 2009$ \\
\hline 9 & $\begin{array}{c}1999- \\
1329\end{array}$ & $\begin{array}{l}\text { Rafael } \\
\text { Gutiérrez }\end{array}$ & Gilberto Méndez Pinzón & $\begin{array}{l}\text { Municipio de } \\
\text { San Gil }\end{array}$ & Existencia contrato & $23 / 05 / 2008$ \\
\hline 10 & $\begin{array}{c}2005- \\
1043\end{array}$ & $\begin{array}{l}\text { Rafael } \\
\text { Gutiérrez }\end{array}$ & $\begin{array}{c}\text { Ingenieros constructores } \\
\text { tecnología y equipo } \\
\text { constructora INECONTE } \\
\text { LTDA }\end{array}$ & $\begin{array}{l}\text { Instituto Nacional de } \\
\text { Vías - INVIAS }\end{array}$ & Nulidad Resolución & $25 / 07 / 2008$ \\
\hline 11 & $\begin{array}{c}2000- \\
2920\end{array}$ & $\begin{array}{l}\text { Solange } \\
\text { Blanco }\end{array}$ & Deprocon Ltda & $\begin{array}{l}\text { Municipio de } \\
\text { Charalá }\end{array}$ & $\begin{array}{c}\text { Liquidación } \\
\text { contrato, responsable } \\
\text { el municipio }\end{array}$ & 04/09/2008 \\
\hline 12 & $\begin{array}{c}2000- \\
2608\end{array}$ & $\begin{array}{l}\text { Solange } \\
\text { Blanco }\end{array}$ & Coormagdalena & $\begin{array}{c}\text { Soc. Ríos } \\
\text { construcciones y } \\
\text { Otro }\end{array}$ & $\begin{array}{l}\text { Liquidación } \\
\text { contrato, pago de } \\
\text { perjuicios }\end{array}$ & $19 / 02 / 2009$ \\
\hline 13 & $\begin{array}{c}2002- \\
350\end{array}$ & $\begin{array}{l}\text { Solange } \\
\text { Blanco }\end{array}$ & Consorcio Construyendo & $\begin{array}{l}\text { E. S. E. Hospital } \\
\text { Psiquiátrico San } \\
\text { Camilo }\end{array}$ & $\begin{array}{c}\text { Nulidad del } \\
\text { contracto, actos } \\
\text { administrativos }\end{array}$ & $11 / 06 / 2009$ \\
\hline 14 & $\begin{array}{c}1998- \\
1586\end{array}$ & $\begin{array}{l}\text { Solange } \\
\text { Blanco }\end{array}$ & Javier López Rojas & $\begin{array}{l}\text { Municipio } \\
\text { de Guaca }\end{array}$ & $\begin{array}{c}\text { Existencia e } \\
\text { incumplimiento del } \\
\text { contrato }\end{array}$ & $09 / 07 / 2009$ \\
\hline 15 & $\begin{array}{c}2000- \\
2535\end{array}$ & $\begin{array}{l}\text { Solange } \\
\text { Blanco }\end{array}$ & Santiago Sánchez Vesga & $\begin{array}{c}\text { Departamento } \\
\text { de Santander y } \\
\text { Municipio de Suratá }\end{array}$ & $\begin{array}{l}\text { Incumplimiento } \\
\text { contrato, caducidad } \\
\text { de la acción }\end{array}$ & $13 / 08 / 2009$ \\
\hline 16 & $\begin{array}{c}2008- \\
891\end{array}$ & $\begin{array}{l}\text { Solange } \\
\text { Blanco }\end{array}$ & Reinaldo Díaz Díaz & Municipio de Vélez & $\begin{array}{c}\text { Incumplimiento } \\
\text { contrato, Nulidad } \\
\text { terminación } \\
\text { unilateral contrato, } \\
\text { perjuicios }\end{array}$ & 08/10/2009 \\
\hline
\end{tabular}

Fuente: La autora

El análisis de cada fallo se realizó según modelo de ficha diseñado para estos efectos $^{7}$, dentro del cual se incluyen, como categorías de análisis de la labor interpretativa, aquellas que se refieren a: (a) Concepción del Derecho o Perspectiva, (b) Fuentes del derecho o Insumos jurídicos, (c) Corrientes Adscritas, (d) Método de Interpretación, (e) Especificaciones del método, (f) Función del Juez, definir si hace una revisión adjetiva o sustancial a fin de resolver el conflicto (g) Racionalidad,

$7 \quad$ La ficha se estructura a partir de cuatro partes: La primera advierte el soporte en grupo y línea de investigación del proyecto; la segunda da cuenta de información necesaria para identificar cada fallo, la tercera corresponde al análisis de la sentencia, incluidas las partes esenciales del fallo como son pretensiones, excepciones, problema jurídico, contrato revisado, hechos relevantes, considerandos (ratio decidendi), y el resuelve; la cuarta parte da razón de la labor interpretativa que identifica las fuentes utilizadas por el TAS y el método de interpretación, a partir de las categorías definidas. 
definir si el juez hace corrección material, es decir, si hace consideraciones de argumentos de orden constitucional y además, si es consecuencialista, es decir, da preponderancia a aspectos económicos y políticos, entre otros y termina por beneficiar a la administración (h) Grado de Discrecionalidad, definir si respecto a la fuente utilizada el juez decide si la fuente dice, no dice o no se sabe si dice en relación con la solución del caso (i) Pureza del método: esta categoría es el valor crítico que se imprime tras el análisis de cada fallo y responde a la coherencia entre la decisión tomada por el TAS y lo determinado en cada una de las categorías que anteceden.

Concluido el análisis de cada fallo, el consolidado se presenta a partir de cinco grupos que refieren los conflictos contractuales solucionados por el TAS en el periodo 2008 - 2009 a saber: (a) incumplimiento, (b) nulidad de Actos Administrativos, (c) ocurrencia de hechos imprevistos y rompimiento del equilibrio económico, (d) existencia del contrato y (e) liquidación judicial. Clasificación que se ha definido para presentar una descripción de dichos conflictos y la caracterización de la solución judicial dada por el TAS a partir del análisis de su labor interpretativa fundada en las categorías enunciadas con antelación.

Como se ha mencionado en reiteradas ocasiones, estas líneas consolidan un avance de investigación que se encuentra antecedido por dos más, uno en virtud del cual se logró una descripción ${ }^{8}$ de la relación jurídica que soporta la contratación con la administración pública, a partir de la cual se hace especial énfasis en los puntos problemáticos de la actividad contractual, máxime cuando la misma persigue el cumplimiento de los fines del Estado ${ }^{9}$ a partir de la colaboración del empresario ${ }^{10}$, quien se vincula con la administración en desarrollo de su actividad económica ${ }^{11}$. El otro a partir del cual se revisó la conformación del sistema de fuentes y sus métodos de interpretación como parámetros mínimos en los que se soporta toda decisión judicial de tal manera que permita una labor interpretativa idónea para dar solución al conflicto sometido a conocimiento, a partir de esta revisión se logran establecer

8 Para ello ver publicaciones precedentes: Reyes, 2010, p. $392-411$ y Reyes, 2011, pp. $263-280$.

9 Estos son los consagrados en la Constitución Política de Colombia, especialmente “(...) servir a la comunidad, promover la prosperidad y garantizar la efectividad de los principios, derechos y deberes consagrados en la Constitución (...)" (CPC, 1991. Art. 2) así como la prestación de servicios, lo que exige a la administración el despliegue de la función pública y específicamente de la actividad contractual.

10 A partir de la actividad contractual de la Administración en torno a los fines del Estado, se cumple uno de los propósitos del constituyente: 'la vinculación de los particulares al progreso, al desarrollo de una sociedad que descansa sobre un mandato superior que no es posible eludir: el estado social de derecho, concepto constitucional que nos atribuye a todos Estado y administrados la responsabilidad del cumplimiento de sus cometidos. (Mier, 2004, 60).

11 De acuerdo a la disposición constitucional a partir de la cual la actividad económica y la libertad de empresa son libres (CPC, 1991. Art. 333) 
las categorías de análisis que sirvieron para adelantar el análisis de cada fallo objeto de estudio.

\section{AVANCE O RESULTADO DE INVESTIGACIÓN}

Los resultados de esta fase del proyecto pueden describirse a partir de dos partes. La primera referida a los conflictos contractuales del empresario con la administración pública, resueltos por el TAS. La segunda describe los hallazgos en punto de la labor interpretativa del TAS, que permiten consolidar los resultados a partir de los mismos grupos definidos por tipo de conflicto contractual y en virtud de los cuales se muestra la tendencia del TAS a partir de gráficas de las categorías, que en cada grupo, muestran variables.

\section{Principales conflictos contractuales en Santander}

De la solución dada por el TAS en los fallos, objetos de estudio, se encuentra que los principales conflictos en Santander giran en torno al incumplimiento del contrato $^{12}$, nulidad de actos administrativos ${ }^{13}$, ocurrencia de hechos imprevisibles y rompimiento del equilibrio económico ${ }^{14}$, existencia del contrato $^{15}$ y liquidación judicial del contrato ${ }^{16}$. Estos cinco conflictos agrupan los 16 fallos analizados y pueden ubicarse territorialmente como se muestra en el Mapa 1.

12 Los fallos referentes a incumplimiento del contrato se encuentran señalados en el Mapa con el color amarillo, su radicado y tipo de contrato.

13 Los referentes a nulidad de actos administrativos se encuentran señalados en el Mapa con el color rojo, su radicado y tipo de contrato.

14 Los referentes a ocurrencia de hechos previsibles y rompimiento del equilibrio económico se encuentran señalados en el Mapa con el color gris, su radicado y tipo de contrato.

15 Los referentes a inexistencia del contrato se encuentran señalados en el Mapa con el color verde, su radicado y tipo de contrato.

16 Los referentes a liquidación judicial del contrato se encuentran señalados en el Mapa con el color morado, su radicado y tipo de contrato. 
Mapa 1. Conflictos ubicados de acuerdo al lugar de ejecución del contrato

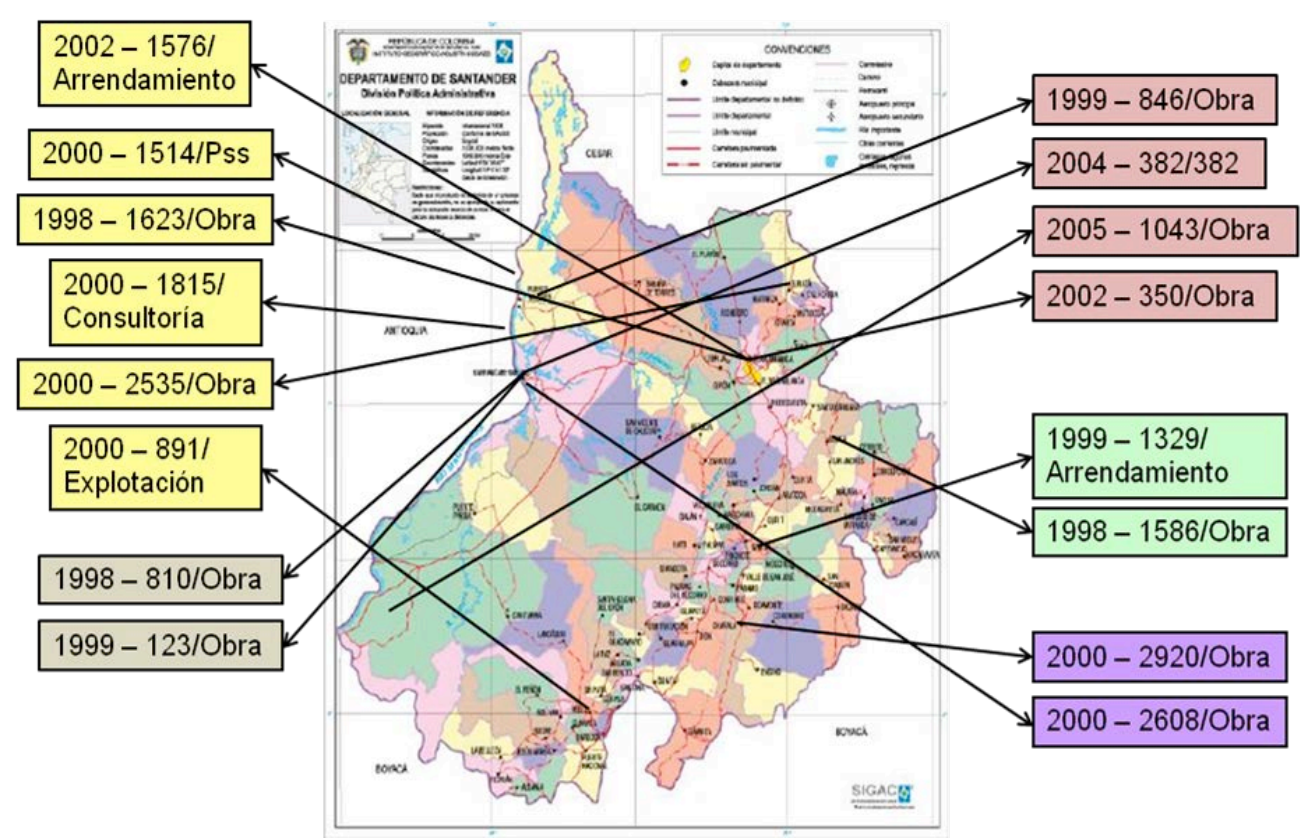

Fuente: La autora

Es importante recordar que el TAS es el órgano competente para resolver los conflictos contractuales del empresario con la administración pública, a través de la acción contractual, de acuerdo a lo consagrado en el artículo 87 del CCA, n virtud del cual Cualquiera de las partes de un contrato estatal podrá pedir que se declare su existencia o su nulidad y que se hagan las declaraciones, condenas o restituciones consecuenciales, que se ordene su revisión, que se declare su incumplimiento y que se condene al responsable a indemnizar los perjuicios y que se hagan otras declaraciones y condenas.

En este sentido, las circunstancias fácticas que rodearon cada uno de los fallos analizados, y en consecuencia el conflicto contractual solucionado, se pueden resumir atendiendo a la indicación del negocio jurídico celebrado y su objeto y a los conflictos suscitados -los cuales pueden inferirse desde las pretensiones de la demanda-.

En relación con el negocio jurídico que originó cada uno de los conflictos ventilados ante el TAS encontramos que se destacan el contrato de obra-suscrito para 
colaborar con ECOPETROL ${ }^{17}$, el INVÍAS ${ }^{18}$, el Municipio de Charalá $^{19}$, el Municipio de Bucaramanga ${ }^{20}$, la Corporación Autónoma de Río Grande ${ }^{21}$, el Departamento de Santander - Municipio de Suratá, ${ }^{22}$ el Municipio de Guaca ${ }^{23}$ y el ESE Hospital psiquiátrico San Camilo ${ }^{24}$-; el contrato de arrendamiento -suscrito para colaborar con el Municipio de San Gil ${ }^{25}$ y el INPEC ${ }^{26}$-; el contrato de prestación de servicios -suscrito para colaborar con el Departamento de Santander ${ }^{27}$ y el Municipio de Barrancabermeja ${ }^{28}$-; el contrato de explotación -suscrito para colaborar con el Municipio de Vélez ${ }^{29}$; y el contrato de consultoría - suscrito para colaborar con el Departamento de Santander ${ }^{30}$.

Frente a las causales propias de cada conflicto, se toma como punto de partida los cinco grupos referidos por tipo de conflicto. Así, el incumplimiento del contrato ${ }^{31}$ se presentó en dos vías. Aquellos conflictos originados por el incumplimiento

17 TRIBUNAL ADMINISTRATIVO DE SANTANDER. Proceso 1998 - 810, Sentencia del 21 de Agosto de 2009. Mg. Ponente. Milciades Rodríguez Quintero. Y TRIBUNAL ADMINISTRATIVO DE SANTANDER. Proceso 1999 - 123, Sentencia del 29 de Agosto de 2008. Mg. Ponente. Francy del Pilar Pinilla Pedraza.

18 TAS. Proceso 2005 - 1043, Sentencia del 25 de Julio de 2008. Mg. Ponente. Rafael Gutiérrez Solano.

19 TAS. Proceso 2000 - 2920, Sentencia del 4 de Septiembre de 2008. Mg. Ponente. Solange Blanco Villamizar.

20 TAS. Proceso 1998 - 1623, Sentencia del 28 de Mayo de 2009. Mg. Ponente. Francy del Pilar Pinilla Pedraza.

21 TAS. Proceso 1999 - 846, Sentencia del 22 de Enero de 2009. Mg. Ponente. Milciades Rodríguez Quintero; y TRIBUNAL ADMINISTRATIVO DE SANTANDER. Proceso 2000 - 2608, Sentencia del 19 de Febrero de 2009. Mg. Ponente. Solange Blanco Villamizar.

22 TAS. Proceso 2000 - 2535, Sentencia del 13 de Agosto de 2009. Mg. Ponente. Francy del Pilar Pinilla Pedraza.

23 TAS. Proceso 1998 - 1586, Sentencia del 9 de Julio de 2009. Mg. Ponente. Solange Blanco Villamizar.

24 TAS. Proceso 2002 - 350, Sentencia del 11 de Junio de 2009. Mg. Ponente. Solange Blanco Villamizar.

25 TAS. Proceso 1999 - 1329, Sentencia del 23 de Mayo de 2008. Mg. Ponente. Rafael Gutiérrez Solano.

26 TAS.. Proceso 2002 - 1576, Sentencia del 27 de Agosto de 2009. Mg. Ponente. Julio Édisson Ramos Salazar.

27 TAS. Proceso 2000 - 1514, Sentencia del 31 de Julio de 2008. Mg. Ponente. Milciades Rodríguez Quintero.

28 TAS. Proceso 2004 - 382, Sentencia del 9 de Julio de 2009. Mg. Ponente. Francy del Pilar Pinilla Pedraza.

29 TRIBUNAL ADMINISTRATIVO DE SANTANDER. Proceso 2000 - 891, Sentencia del 8 de Octubre de 2009. Mg. Ponente. Solange Blanco Villamizar.

30 TRIBUNAL ADMINISTRATIVO DE SANTANDER. Proceso 2000 - 1815, Sentencia del 10 de Diciembre de 2009. Mg. Ponente. Francy del Pilar Pinilla Pedraza.

31 El incumplimiento del contrato fue debatido en las siguientes sentencias del TAS: Proceso $2002-$ 1576, Sentencia del 27 de Agosto de 2009. Mg. Ponente. Julio Edison Ramos Salazar.; Proceso 2000 - 1514, Sentencia del 31 de Julio de 2008. Mg. Ponente. Milciades Rodríguez Quintero.; Proceso 1998 - 1623, Sentencia del 28 de Mayo de 2009. Mg. Ponente. Francy del Pilar Pinilla Pedraza.; Proceso 2000 - 1815, Sentencia del 2810 de Diciembre de 2009. Mg. Ponente. Francy del Pilar Pinilla Pedraza.; Proceso 2000 - 2535, Sentencia del 13 de Agosto de 2009. Mg. Ponente. Francy del Pilar Pinilla Pedraza.; y Proceso 2000 - 891, Sentencia del 8 de Octubre de 2009. Mg. Ponente. Solange Blanco Villamizar. 
de la administración, esto es alegado por el empresario; y el incumplimiento del empresario, esto es el alegado por la Administración. Este tipo de conflictos giraron en torno a contratos de prestación de servicios, obra, arrendamiento, explotación y consultoría. Las principales razones de incumplimiento se reducen a el no pago de anticipos, reajustes de precios y demás dineros a favor del contratista, la omisión de la Administración para permitir el desarrollo del objeto -que genera obstáculos para su desarrollo-, tales como otorgamiento de permisos, demoras en la legalización del contrato, iliquidez para el pago y la reducción de horarios y de espacios, la terminación unilateral del contrato y la negación de la revisión de precios ante el eventual rompimiento de la ecuación contractual.

Los conflictos en torno a la nulidad de actos administrativos ${ }^{32}$ proferidos en el proceso de selección del contratista o durante la ejecución del contrato, se produjo en contratos de obra suscritos como producto de un proceso de licitación. En este grupo encontramos un caso en el que se alega la nulidad del acto de adjudicación y demás relacionados y del contrato celebrado por cuanto se vulneraron derechos del oferente, es decir, fue eliminado de la lista de elegibles -tenidas todas las posibilidades para obtener la adjudicación del contrato- el empresario fue sacado del proceso de licitación, actos que fueron proferidos y realizados antes de la adjudicación del contrato. Así como otro caso en el que la nulidad alegada es del acto administrativo que declara la ocurrencia del riesgo de estabilidad y ordena hacer efectiva la póliza suscrita como amparo, acto que es proferido durante la ejecución del contrato.

La ocurrencia de hechos imprevisibles y el rompimiento de equilibrio económico $^{33}$ se generó en ejecución de un contrato de obra, en virtud del cual el empresario alega perjuicios representados en pérdida de tiempo y dinero pues fue necesaria la suspensión del contrato, en varias oportunidades, y la construcción de obras adicionales, lo que le impidió cumplir con el contrato en el término indicado y ocasionó pérdidas económicas. Los hechos imprevistos alegados responden a cuestiones de orden público en el lugar de ejecución del contrato (Paros cívicos, Paros Sindicales), así como al desarrollo de algunas actividades de la Administración (Visitas Presidenciales) y finalmente a la falta de diseños para la construcción de la obra -diseños que eran responsabilidad de la Administración-.

32 La nulidad de actos administrativos fue debatida en las siguientes sentencias del TAS: Proceso 1999 - 846, Sentencia del 22 de Enero de 2009. Mg. Ponente. Milciades Rodríguez Quintero.; Proceso 2004 - 382, Sentencia del 9 de Julio de 2009. Mg. Ponente. Francy del Pilar Pinilla Pedraza.; Proceso 2005 - 1043, Sentencia del 25 de Julio de 2008. Mg. Ponente. Rafael Gutierrez Solano.; y Proceso 2002 - 350, Sentencia del 11 de Junio de 2009. Mg. Ponente. Solange Blanco Villamizar.

33 La ocurrencia de hechos imprevisibles y el rompimiento del equilibrio económico fueron debatidos en las siguientes sentencias del TAS: Proceso 1998 - 810, Sentencia del 21 de Agosto de 2009. Mg. Ponente. Milciades Rodríguez Quintero.; y Proceso 1999 - 123, Sentencia del 29 de Agosto de 2008. Mg. Ponente. Francy del Pilar Pinilla Pedraza. 
Por su parte, la existencia del negocio jurídico ${ }^{34}$, los conflictos se presentaron en torno a un contrato de arrendamiento que fue suscrito de manera verbal, que se pone de manifiesto por el incumplimiento de la administración en el no pago de los servicios prestados por el empresario.

Finalmente, las diferencias surgidas en torno a la liquidación del contrato ${ }^{35}$, se presentaron en desarrollo de contratos de obra. Una primera circunstancia se presenta por las negativas de la Administración de recibir la obra contratada y la retención de los pagos adeudados al contratista y en consecuencia éste solicita la liquidación judicial del contrato. Otro evento se da por la ocurrencia de liquidación unilateral del contrato por parte de la Administración con ocasión de la destrucción de la obra por acciones del río, alegado además el incumplimiento del contratista y ordenado hacer efectiva la póliza de cumplimiento.

De esta manera se describen los conflictos contractuales del empresario con la administración pública, de los cuales el TAS profirió solución judicial en el periodo $2008-2009$

\section{Caracterización de la solución judicial del TAS}

La caracterización de la solución judicial dada por el TAS, a los conflictos contractuales descritos en el punto anterior, se hace a partir de la revisión de la labor interpretativa del órgano colegiado según las categorías definidas.

Antes de describir, por grupos de conflicto, la labor interpretativa del TAS, es importante aclarar que en los casos de incumplimiento el TAS abordó un estudio adjetivo como requisito para hacer el análisis de fondo del conflicto y en un dos de seis $\operatorname{casos}^{36}$ pudo trascender a dicha revisión procesal, pues en los demás se encontró que operó la caducidad de la acción, hecho que le impidió discernir sobre el fondo del conflicto y en consecuencia se negaron las pretensiones. En los demás asuntos, es decir, los de posible nulidad, declaratoria de existencia del contrato, ocurrencia de hechos imprevisibles y rompimiento del equilibrio económico y liquidación del contrato, el estudio del conflicto pudo hacerse de fondo, pues el TAS revisa presupuestos procesales y excepciones de carácter adjetivo; pero en ningún caso impide hacer el estudio de fondo pretendido.

34 La existencia del contrato fue discutida en las siguientes sentencias del TAS: Proceso 1999 - 1329 , Sentencia del 23 de Mayo de 2008. Mg. Ponente. Rafael Gutiérrez Solano.; y Proceso 1998 - 1586, Sentencia del 9 de Julio de 2009. Mg. Ponente. Solange Blanco Villamizar.

35 La liquidación de contrato fue dirimida en las siguientes sentencias del TAS: Proceso 2000 - 2920, Sentencia del 4 de Septiembre de 2008. Mg. Ponente. Solange Blanco Villamizar.; y Proceso 2000 - 2608, Sentencia del 19 de Febrero de 2009. Mg. Ponente. Solange Blanco Villamizar.

36 Proceso 1998 - 1623, Sentencia del 28 de Mayo de 2009. Mg. Ponente. Francy del Pilar Pinilla Pedraza. Proceso 2000 - 891, Sentencia del 8 de Octubre de 2009. Mg. Ponente. Solange Blanco Villamizar. 
Continuar con la descripción de la labor interpretativa del máximo órgano de la jurisdicción contencioso administrativa, en Santander, requiere retomar los cinco grupos de conflicto definidos en el punto anterior, se precisa que en la mayoría de los eventos, el TAS resolvió los casos sometidos a su conocimiento en contra de los intereses del empresario involucrado en la relación contractual, dando la razón a la Administración, salvo en tres eventos que serán detallados más adelante.

De allí que la labor interpretativa permite identificar los insumos empleados por el TAS para fallar en contra de los intereses del empresario, esto a partir de las categorías definidas por cuanto,

Las implicaciones del ordenamiento jurídico en la solución pacífica de conflictos debe estudiarse desde un enfoque integral; desde el punto de vista de las relaciones sistemáticas que se gestan entre las concepciones constitucionales, legales y contractuales, las cuales deben respetar las gradas de jerarquía y validez que se tejen entre cada una de estas fuentes de derecho. (Delgado, 2010, p. 411)

\subsection{Solución judicial a conflictos sobre incumplimiento del contrato}

La labor interpretativa del TAS, en la solución judicial dada a los conflictos sobre incumplimiento del contrato se caracterizan por un mayor acento en la utilización de insumos o fuentes del derecho de carácter legal, circunstancia que llama la atención pues la principal fuente debería ser el contrato por tratarse de conflictos derivados de la ejecución del mismo, sin embargo en sólo dos de seis eventos el TAS acude al acuerdo de voluntades suscrito como fuente o insumo de su decisión. En relación con los insumos jurídicos o fuentes, es importante resaltar los esfuerzos realizados por el TAS por integrar la jurisprudencia del Consejo de Estado (órgano superior dentro de la jurisdicción) con el ánimo de respetar el precedente y dar respaldo a sus argumentos. La circunstancia descrita se debe a que el TAS realizó un análisis adjetivo en torno a la caducidad de la acción contractual por lo que el sistema de fuentes en estos casos se encuentra integrado por la ley contractual, la ley de procedimiento y además por la jurisprudencia aplicable para definir si la misma opera o no. Sólo en los eventos donde el TAS pudo hacer un análisis de fondo el sistema de fuentes se amplía para contemplar el contrato.

Por lo anterior resulta coherente que se haga mayor acento al uso del método de interpretación exegético, en su especificación de análisis gramatical (atendido el tenor literal de la norma) o análisis semántico (atendido el significado de las palabras), en esta misma línea se emplea el método lógico a partir del argumento de contrariedad y se destaca el uso paralelo de métodos como el histórico en su especificidad jurídica (a fin de reconstruir la evolución normativa de la institución) y del método sistemático en su especificidad de Integración de la institución por la división del ordenamiento jurídico y la Integración del contexto social - jurídico - político. 
En este primer grupo puede afirmarse que el TAS cumplió una función declarativa del derecho vigente y se entiende en razón al estudio adjetivo adelantado en la mayoría de los casos, y que en consecuencia hace que el papel del juez se enmarque en una racionalidad limitada en la medida en que con los insumos del ordenamiento jurídico se toma la decisión, sin que pueda evidenciarse corrección material pues no se hacen consideraciones de argumentos de orden constitucional, como ya se evidenciaba del sistema de fuentes empleado, evitó también consideraciones de tipo económico o político, pues el fundamento en todo caso es la regla extraída de la ley. Así el TAS gozó de discrecionalidad pues de las diversas interpretaciones realizadas a las fuentes empleadas, decidió aquella que se ajusta más al caso.

En este sentido, hacer un análisis sobre la pureza del método, entendido como la coherencia entre los insumos o fuentes empleadas, el proceso de interpretación adelantado y la decisión tomada, en la solución judicial dada frente al incumplimiento del contrato se caracterizó por la identificación de la norma aplicable, la interpretación de la misma a fin de identificar los presupuestos de hecho de la norma y confrontarlos con las circunstancias fácticas, así la decisión tomada guarda coherencia con el proceso interpretativo y demás insumos empleados.

La descripción realizada de los resultados muestra variaciones en varias categorías analizadas: en la referida al insumo o fuentes del derecho, al método de interpretación, a las especificaciones del método y al tipo de análisis que se da en la función declarativa del juez, por lo que del análisis de los casos sobre incumplimiento del contrato, pueden graficarse dichas divergencias para evidenciar las tendencias del grupo de los casos sistematizados, habida cuenta de los insumos o fuentes del derecho, los métodos de interpretación, la especificación del método y el análisis en ejercicio de la discrecionalidad (adjetivo o sustancial), de acuerdo a las siguientes representaciones gráficas.

\section{a. Insumos o Fuentes del Derecho}

De los seis fallos analizados todos emplearon la ley como insumo, de esos, cuatro emplearon además la jurisprudencia, dos además el contrato, uno fuente de origen ejecutivo y uno fuentes independientes representadas en actas y demás documentos probatorios (Ver Gráfica 1) 
Gráfica 1. Tendencia en insumos o fuentes del derecho

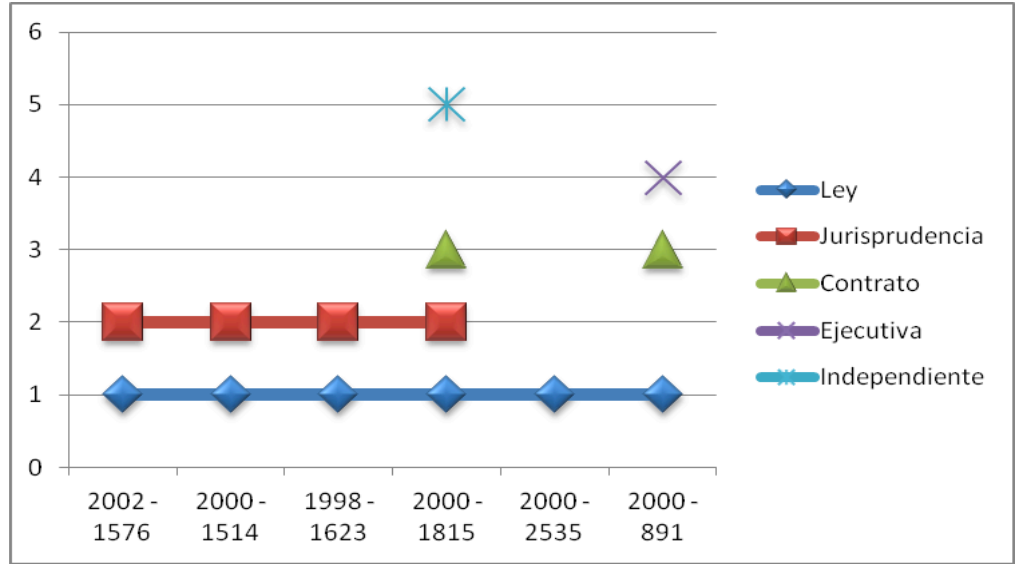

Fuente: La autora

\section{b. Métodos de Interpretación}

En cuanto a los métodos de interpretación, de los seis fallos todos emplearon el método exegético, dos además el lógico, otros dos además el sistemático y uno además el histórico (Ver Gráfica 2).

Gráfica 2. Tendencia en el método de interpretación

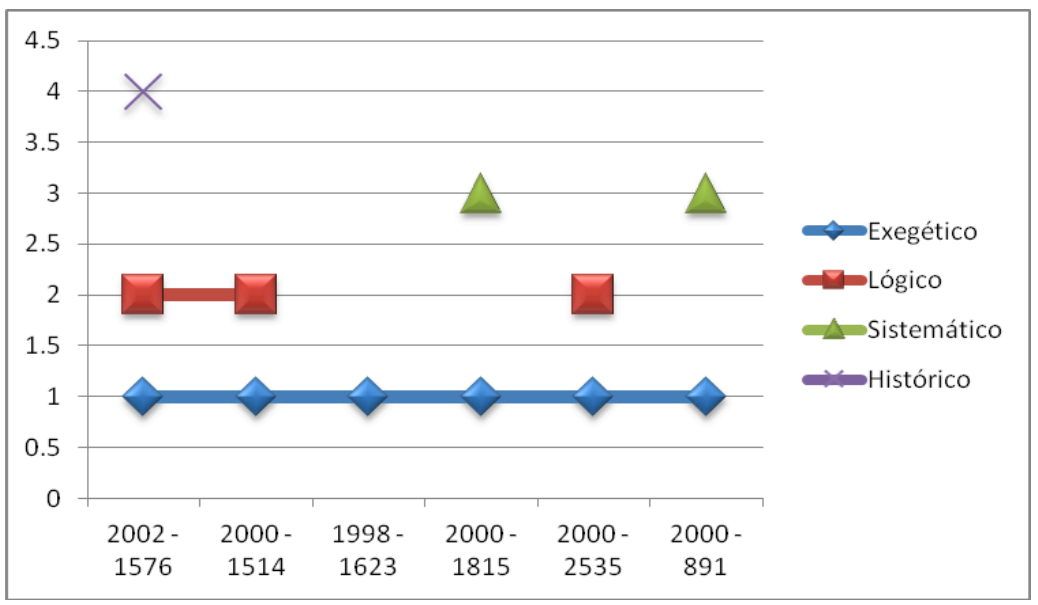

Fuente: La autora 


\section{c. Especificidad del método}

Por su parte las especificaciones del método, el método exegético se especificó a partir del análisis semántico en cuatro casos, el análisis gramatical en cinco y el argumento de contrariedad en dos; el método sistemático se especificó a partir de la integración de la institución en función de la división del ordenamiento en dos casos y la integración del contexto en uno; y el método histórico se especificó a partir de lo jurídico en un caso (Ver Gráfica 3).

Gráfica 3. Tendencia en las especificaciones del método

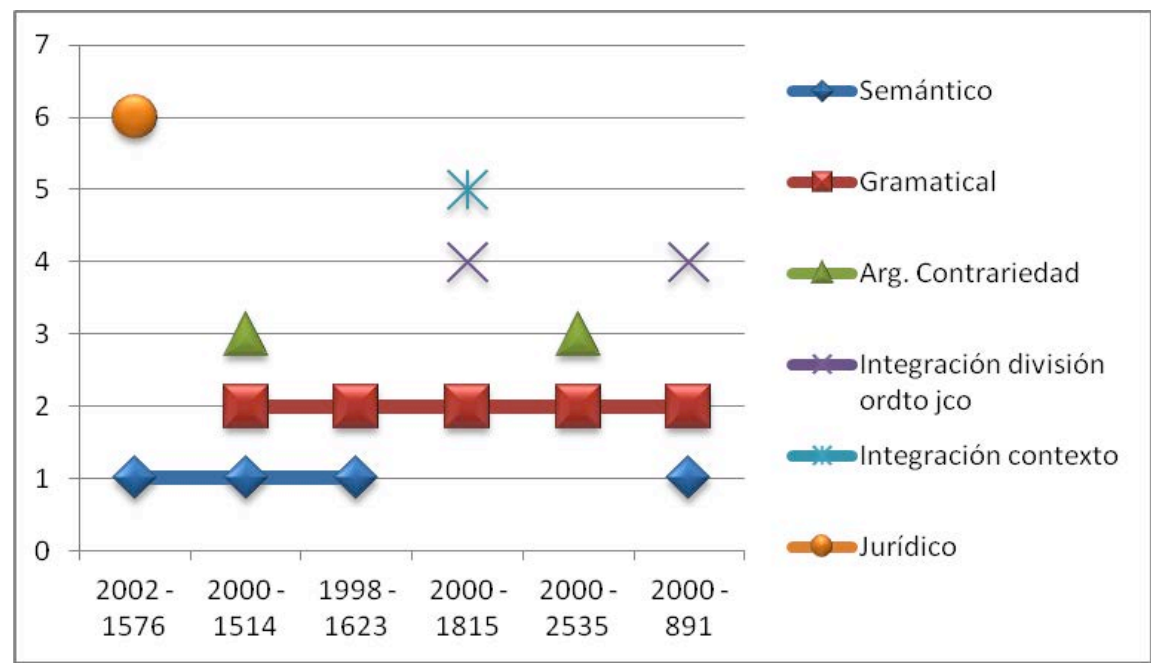

Fuente: La autora

\section{d. Función Declarativa del Juez: Análisis Adjetivo - Análisis Sustancial}

En relación con el tipo de análisis realizado por el TAS en ejercicio de su función declarativa del derecho, se puede observar que de los seis fallos en tres se hizo sólo análisis adjetivo, en uno se hizo sólo análisis sustancial y en dos se hizo primero un análisis adjetivo, que superado, permitió hacer un análisis sustancial (Ver Gráfica 4) 
Gráfica 4. Tendencias en la función declarativa del Juez

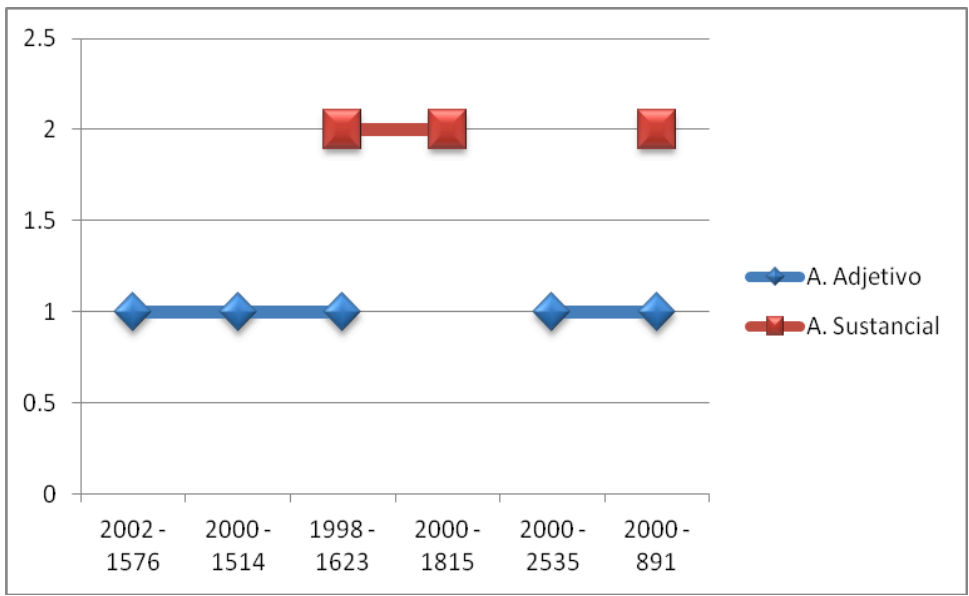

Fuente: La autora

\subsection{Solución judicial a conflictos sobre la nulidad de actos administrativos}

Del análisis del segundo grupo de fallos, se puede observar que el TAS, al momento de resolver conflictos contractuales en torno a la nulidad de actos administrativos, conforma un sistema de fuentes complejo integrado por el contrato y el pliego de condiciones como ley para las partes, la ley en sentido formal, la jurisprudencia como respeto al precedente del Consejo de Estado y fuentes de orden ejecutivo que afectan el negocio objeto de controversia. De manera coherente se emplean métodos de interpretación acordes a cada fuente así para el contrato se usaron las reglas de interpretación contractual contenidas en el Código Civil, para la ley el método exegético en su especificación de análisis gramatical, el método lógico representando en el argumento de reducción al absurdo, el método finalista atendida la finalidad de la norma superior y de la misma ley de contratación estatal y el método sistemático a partir de la integración de la institución en función de la división del ordenamiento jurídico y del precepto constitucional.

Lo anterior permitió al TAS cumplir con una función declarativa del derecho vigente, caracterizada por un análisis adjetivo necesario y un análisis sustancial profundo que le ubica dentro de una racionalidad limitada por las herramientas del ordenamiento empleadas, que le permitió intentar una corrección material por la referencia a consideraciones de orden constitucional e incluso políticas, económicas y del principio de igualdad, como ejercicio consecuencialista en procura de los intereses de la administración y de terceros. 
Las tendencias descritas y que caracterizan la labor interpretativa en la solución de conflictos en torno a la nulidad de actos administrativos, puede ser graficadas de acuerdo a las categorías que más divergencias muestran como son la de insumos o fuentes del derecho, la de métodos de interpretación y su especificación, la de la función del juez al precisar el ejercicio adjetivo o sustantivo, la racionalidad limitada por la corrección material y el consecuencialismo.

Las divergencias de la labor interpretativa del TAS en este segundo grupo se evidenciaron en las categorías de insumos o fuentes del derecho, métodos de interpretación, especificaciones del método, función declarativa y racionalidad, así:

\section{a. Insumos y Fuentes del Derecho}

En torno a los insumos o fuentes del derecho, los cuatro fallos analizados emplearon la ley y la jurisprudencia, adicionalmente en tres de ellos se incluyó como fuente al contrato y al pliego de condiciones y en otras dos, además fuentes de origen ejecutivo (Ver Gráfica 5)

Gráfica No. 5. Tendencias en insumos o fuentes del derecho

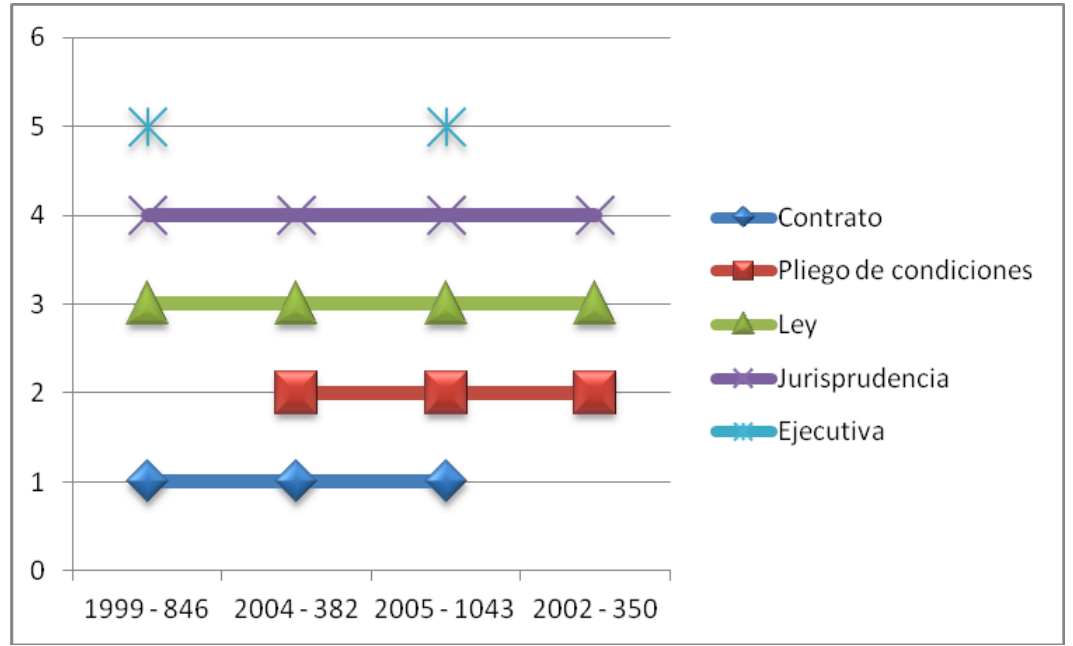

Fuente: La autora 


\section{b. Métodos de interpretación}

Los métodos de interpretación empleados por el TAS en los cuatro fallos analizados, en tres casos correspondió al método exegético, de los cuales en uno se conjuga con el método lógico, y en tres casos al método finalista, de los cuales se conjuga con exegético y sistemático (Ver Gráfica 6).

Gráfica No. 6. Tendencias sobre métodos de interpretación

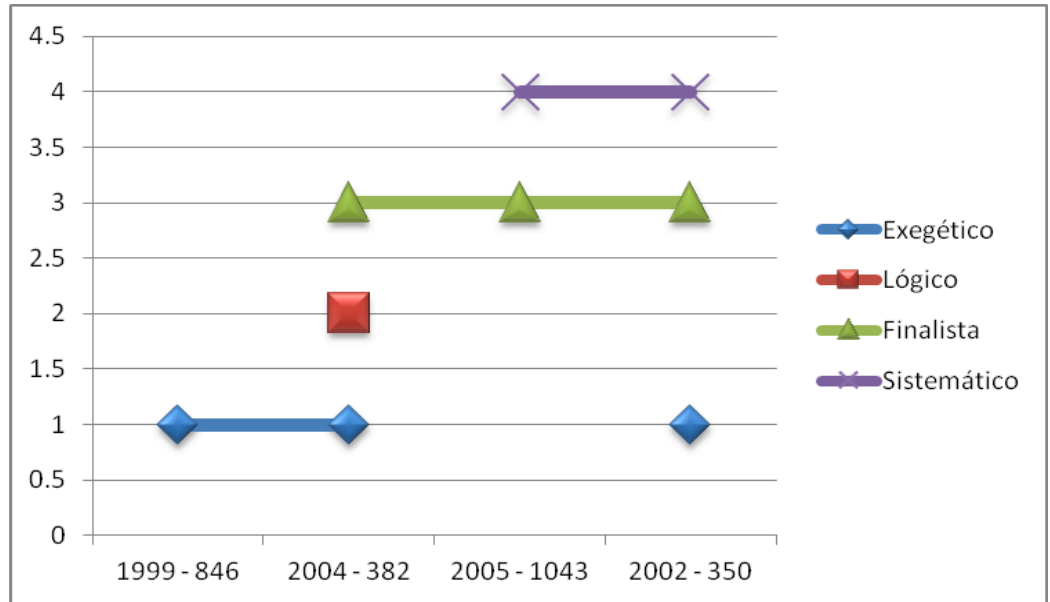

Fuente: La autora

\section{c. Especificaciones del método}

Las tendencias en torno a las especificaciones del método son aún más diversas. Así en tres casos se conjuga la finalidad de la norma superior y la finalidad de la ley, de los cuales dos involucran además la integración de la institución en función de la división del ordenamiento jurídico, en uno la integración a partir del precepto constitucional, en otro la regla de interpretación contractual de la real intención de las partes y en otro el argumento lógico de reducción al absurdo y el análisis gramatical. Se observa un caso independiente en el que sólo se hace uso del análisis gramatical (Ver Gráfica 7) 
Gráfica 7. Tendencias en especificaciones del método

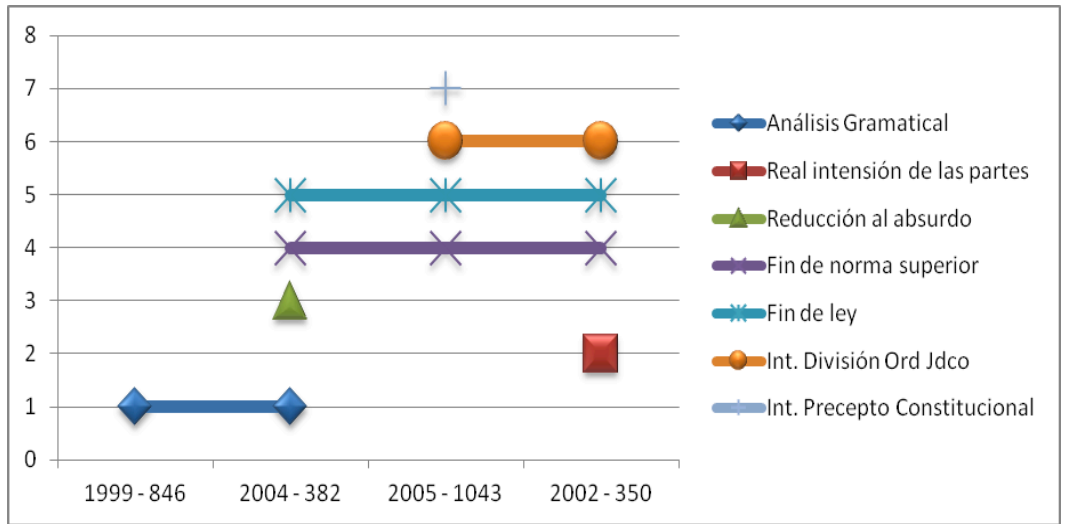

Fuente: La autora

\section{d. Función Declarativa: Análisis adjetivo - Análisis Subjetivo}

La función declarativa del TAS se dio a partir de un análisis sustancial de todos los fallos, lo que explica la diversidad de fuentes, argumentos y métodos de interpretación empleados. De los cuatro fallos sólo en uno hubo necesidad de hacer análisis adjetivo previo, que en todo caso fue superado para dar paso al análisis sustancial (Ver Gráfica 8)

Gráfica 8. Tendencias en función declarativa del Juez

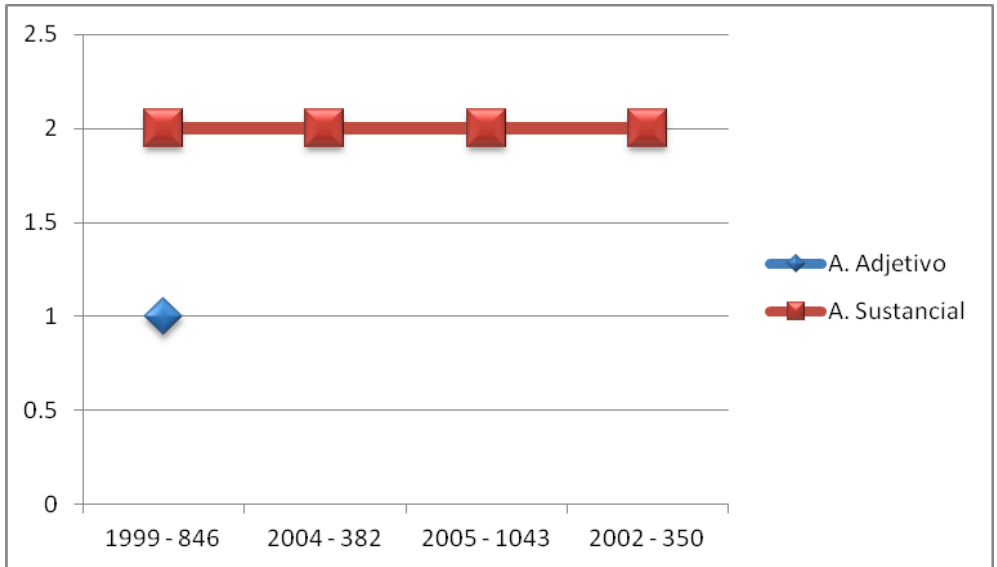

Fuente: La autora 


\section{e. Racionalidad: Corrección Material - Consecuencialismo}

Una quinta representación gráfica se logra en este grupo de fallos, al atender a los argumentos en torno a corrección material o a la consideración de aspectos económicos, políticos, de igualdad y sobre los efectos del fallo, esgrimidos por el TAS. De los cuatro fallos analizados, existe un caso independiente en el que se presenta consecuencialismo, en los otros tres se intenta la corrección material, dentro de los cuales dos se conjuga además el consecuencialismo (Ver Gráfica 9)

Gráfica 9. Tendencias en la racionalidad del Juez

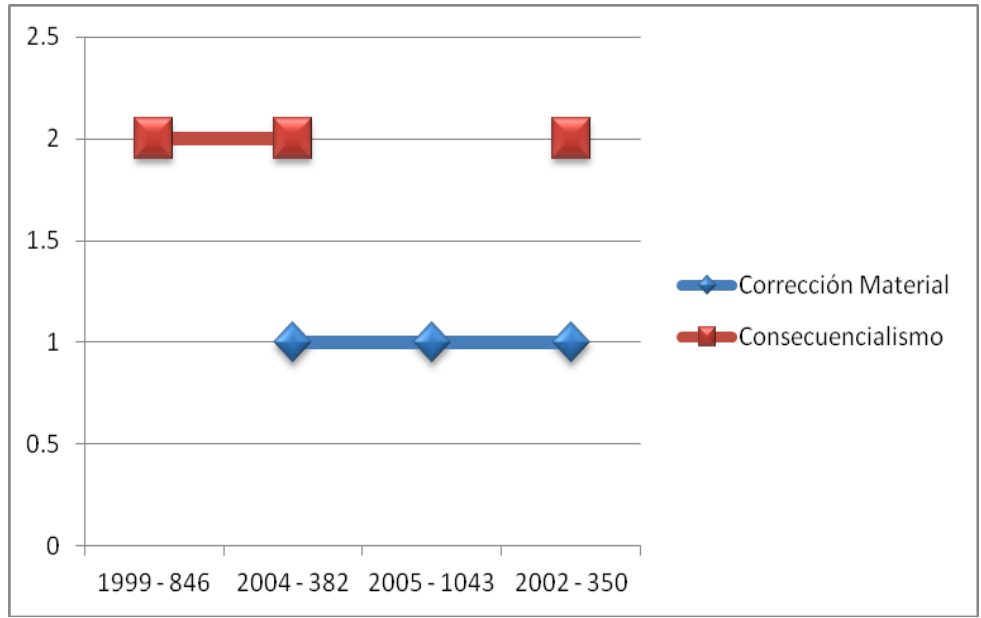

Fuente: La autora

\subsection{Solución Judicial a conflictos sobre la ocurrencia de hechos imprevisibles y rompimiento del equilibrio económico}

La solución judicial dada por el TAS a los conflictos en torno a la ocurrencia de hechos imprevistos y el rompimiento del equilibrio económico evidencia el uso de un sistema de fuentes complejo integrado por la Constitución Política, el contrato, la ley y la jurisprudencia, en consecuencia los métodos de interpretación en los que se hace más acento son el histórico, a fin de revisar la evolución histórica de la norma, el exegético en su análisis semántico y sobre todo en el uso de las reglas de interpretación contractual del Código Civil (real intensión de las partes y tenor literal de las palabras), el sistemático a partir de la integración de la institución desde el precepto constitucional y la integración del contexto y el finalista a partir del reconocimiento de la finalidad de la ley. 
Estos insumos o fuentes del derecho y el ejercicio de interpretación alrededor de ellas permiten al TAS una función declarativa del derecho vigente a partir de un estudio de fondo, una racionalidad limitada que intenta una corrección material por la consideración de argumentos de orden constitucional y una discrecionalidad coherente que le permite discernir lo que cada fuente dice o no respecto al caso concreto. Todo lo anterior demuestra una pureza del método basada en la coherencia de la labor interpretativa del TAS.

Las tendencias descritas en este tercer grupo, pueden ser representadas gráficamente a partir de las categorías que presentan mayor divergencia como son: insumos o fuentes del derecho, métodos de interpretación y especificidad del método.

\section{a. Insumos o Fuentes del Derecho}

En relación con los insumos, de los dos fallos que conforman este grupo, en uno se emplearon como fuentes la Constitución, la Ley, el contrato y la jurisprudencia, mientras que en el otro sólo se emplearon la ley y la jurisprudencia (Ver Gráfica 10)

Gráfica 10. Tendencias en insumos o fuentes del derecho

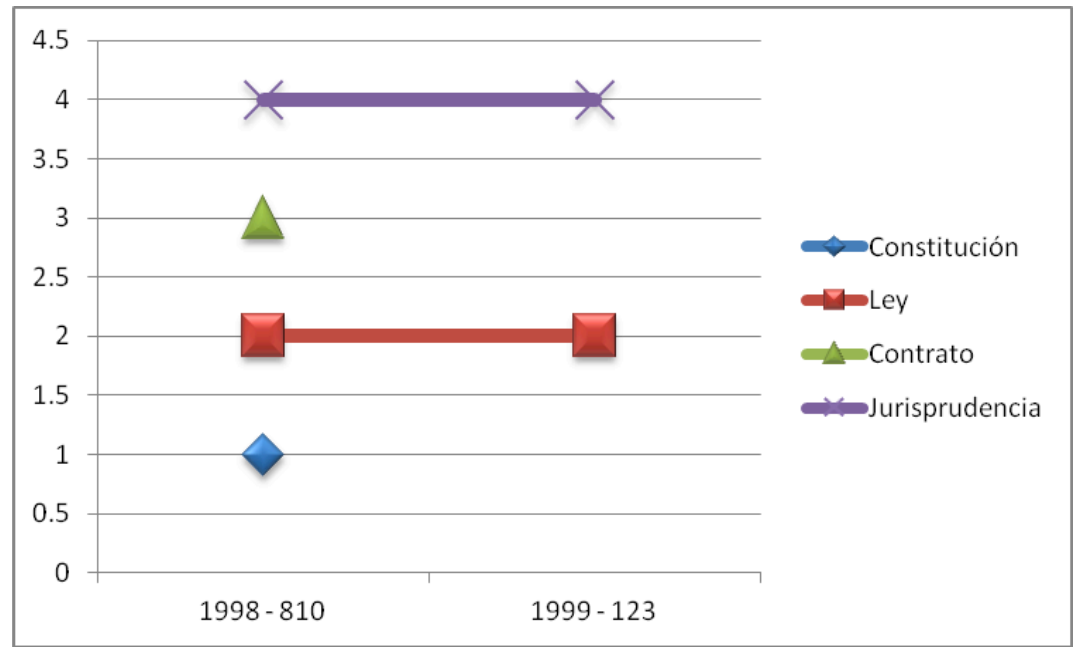

Fuente: La autora 


\section{b. Métodos de Interpretación}

Respecto a los métodos de interpretación, la tendencia en uno de los fallos fue utilizar métodos como el histórico, exegético y sistemático, mientras que en el otro, además del exegético y el sistemático, se utilizó el finalista (Ver Gráfica 11)

Gráfica No. 11. Tendencias sobre métodos de interpretación

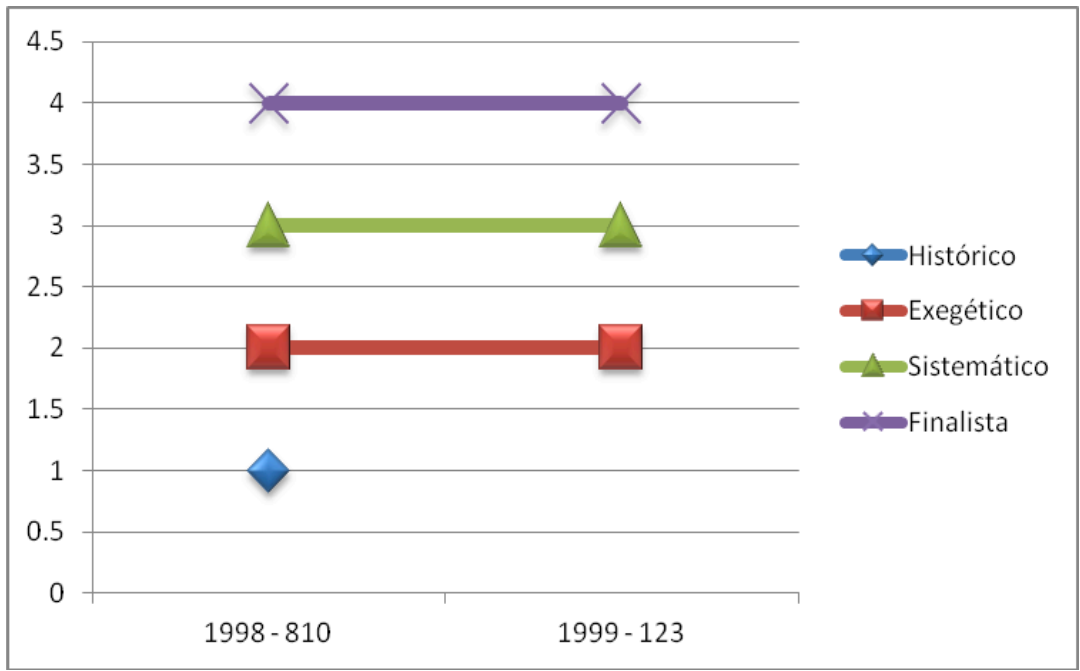

Fuente: La autora

\section{c. Especificaciones del Método}

En relación con las especificaciones del método, en uno de los fallos se hace especificación jurídica del método histórico, además de análisis semántico se aplican reglas de interpretación contractual y se integra la institución a partir del precepto constitucional; mientras que en el otro, además del análisis semántico se integra la institución a partir del contexto y se atiende a la finalidad de la ley (Ver Gráfica 12) 
Gráfica No. 12. Tendencias sobre especificaciones del método

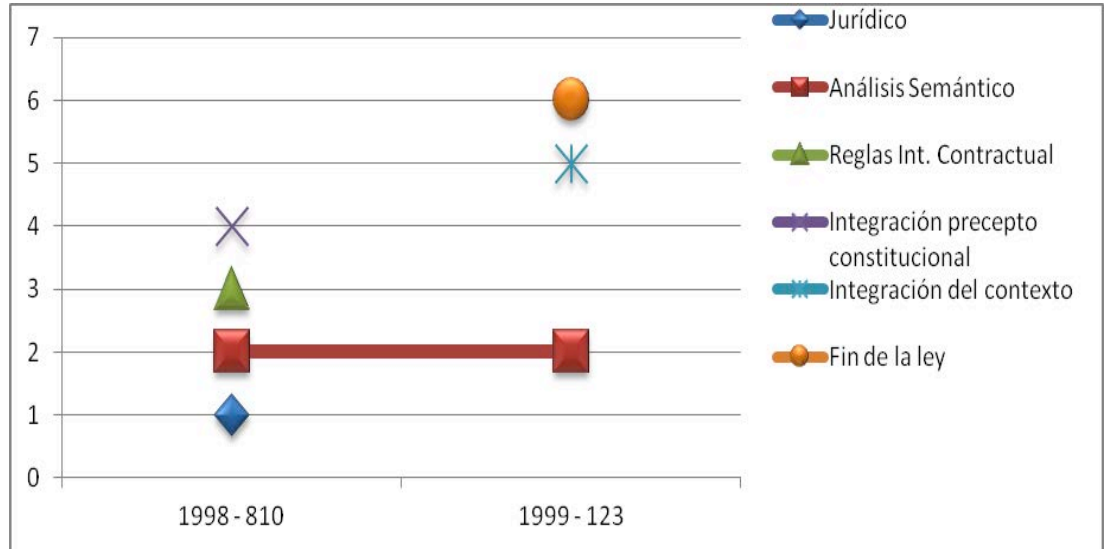

Fuente: La autora

\subsection{Solución Judicial a conflictos sobre la existencia del contrato}

La solución judicial del TAS en torno a la existencia del contrato, retoma el estilo caracterizado en el primer grupo, es decir, los insumos o fuentes del derecho aplicadas se reducen a la ley y a la jurisprudencia, incluido además el contrato, sin embargo, esta inclusión es excepcional pues el caso giraba en torno a un conflicto por un contrato declarado nulo en otro proceso. En todo caso puede afirmarse que los insumos o fuentes del derecho se reducen en comparación con los grupos dos y tres ya descritos.

Como consecuencia de la utilización de la ley, el contrato y la jurisprudencia como fuentes, el método de interpretación empleado es el exegético en su especificación de análisis gramatical, por lo que la función del juez es declarativa del derecho vigente limitada en un caso al análisis sustancial y en el otro al análisis adjetivo, la racionalidad es aún limitada y la discrecionalidad se reduce a la confrontación de las circunstancia fácticas con los presupuestos de hecho de la norma.

Así respecto a la pureza del método es limitada la referencia que pueda hacerse, pues el ejercicio del TAS se reduce a la identificación de la norma aplicable, la aclaración de las circunstancias fácticas y la conclusión de acuerdo a su confrontación con los presupuestos de hecho de la norma. Esto se debe a que los conflictos en torno a la existencia del contrato se fundan en el carácter solemne del contrato estatal, por lo que el análisis de fondo es limitado. Del ejercicio interpretativo elaborado, se deduce la decisión de negar las pretensiones de la demanda.

Las tendencias que caracterizan a este grupo, pueden ser representadas a partir de las divergencias en sus categorías, sin embargo, por la sencillez de la labor 
interpretativa, sólo pueden ser graficadas las categorías de insumos o fuentes del derecho y de función del juez por el análisis adjetivo o sustancial realizado.

\section{a. Insumos o fuentes del derecho}

Los insumos o fuentes del derecho utilizados por el TAS en los dos fallos que conforman este grupo, en un caso se reduce a la ley y la jurisprudencia; mientras que en el otro a la ley y el contrato (Ver Gráfica 13).

Gráfica 13. Tendencias en torno a insumos o fuentes del derecho

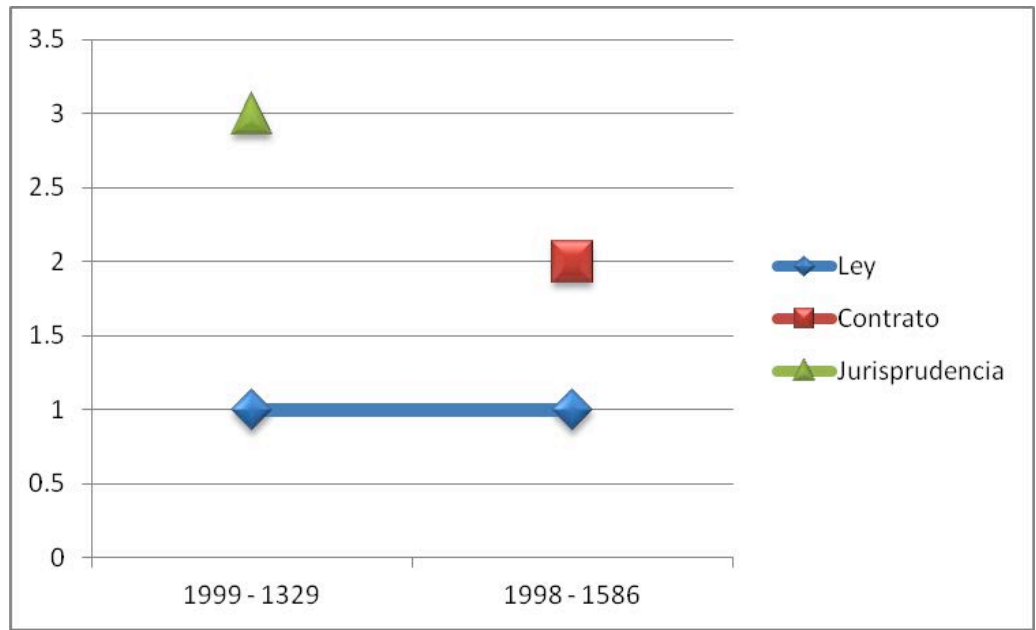

Fuente: La autora

\section{b. Función Declarativa del Juez: Análisis Adjetivo - Análisis Sustancial}

Respecto a la función declarativa del TAS, y atendiendo a la sencillez del ejercicio interpretativo del TAS, de los dos fallos que conforman este grupo, en uno se hizo análisis adjetivo que en últimas impidió hacer un análisis de fondo, mientras que en el otro caso fue posible el análisis de fondo (Ver Gráfica 14) 
Gráfica No. 14. Tendencias sobre función declarativa del Juez

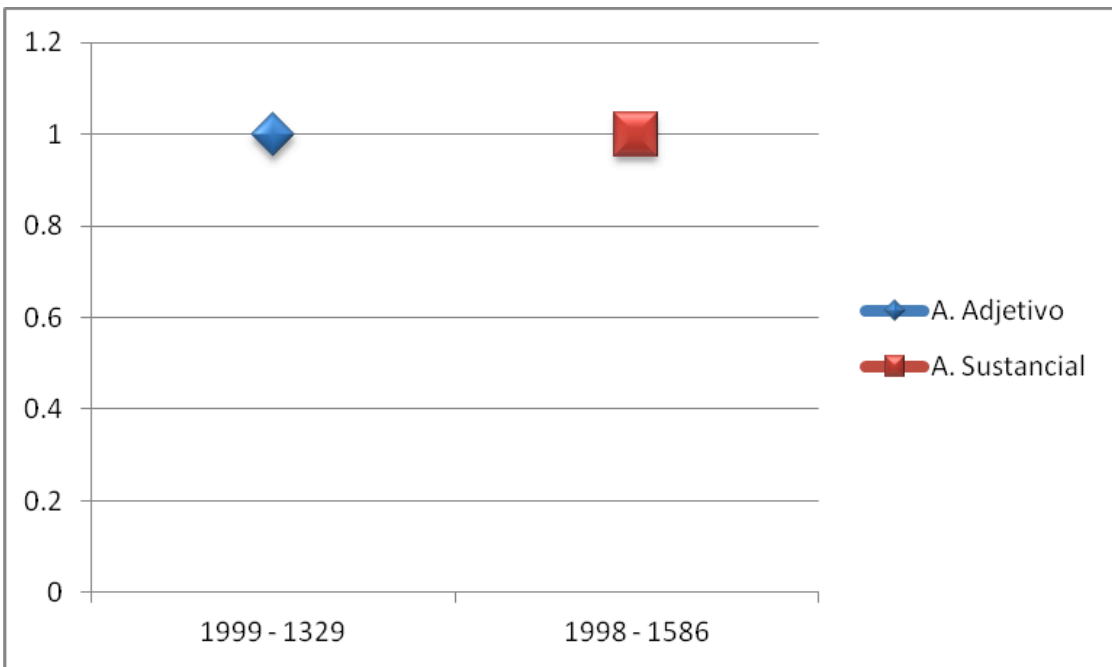

Fuente: La autora

\subsection{Solución Judicial a conflictos en torno a la liquidación judicial del contrato}

La solución judicial dada por el TAS a los conflictos en torno a la liquidación del contrato, se encuentra integrada por dos fallos que accedieron a las pretensiones del demandante y a pesar de que también se hace un ejercicio interpretativo sencillo, es comprensible que se debe al tema objeto de conflicto, esto es, la procedencia de la liquidación judicial del contrato.

Del análisis de los fallos que integran este grupo, se encuentra que los insumos o fuentes del derecho empleadas por el TAS son la ley, el contrato y la jurisprudencia, insumos interpretados a través del método exegético especificado a partir del análisis gramatical de la ley y a la aplicación de las reglas de interpretación contractual (real intensión de las partes). Así la función del TAS fue declarativa del derecho vigente a partir de un análisis sustancial del conflicto y las normas que le son aplicables, de donde se define una racionalidad limitada por el empleo de las herramientas propias del ordenamiento jurídico y la discrecionalidad representada en la identificación de la norma aplicable a partir de su interpretación.

En este sentido, la pureza del método se reduce a la confrontación de las circunstancias fácticas con los presupuestos de hecho de la norma a fin de aplicar la conclusión que le sigue lógicamente, conclusión que se traduce en la decisión de declarar la liquidación judicial del contrato, accediendo así a las pretensiones de la demanda. 
Según la forma en la que cada categoría se define en este grupo, no se presentan divergencias dentro de las mismas, por lo que no requieren de representación gráfica.

De esta manera se presentan los avances del análisis realizado a partir de la definición de las categorías mencionadas y desarrolladas por cada grupo, así queda caracterizada la solución judicial de los conflictos contractuales del empresario con la administración pública en Santander.

\section{Discusión o Conclusiones}

La importancia del estudio realizado y de la conclusión obtenida a partir del mismo, reviste gran importancia por la naturaleza de la relación en conflicto, esto es, la relación contractual del empresario con la Administración Pública. Esto por las finalidades que persigue la actividad contractual de la administración -cumplimiento de los fines impuestos al Estado por la Constitución Política- y el papel del empresario dentro de dicha actividad -colaborar a la administración en el cumplimiento de los fines estatales.

En consecuencia, dentro de una relación necesaria, como es la contractual del empresario con la administración pública, y caracterizada por circunstancia y conflictos de índole económico - por la contribución al desarrollo económico y social del país- la solución judicial que se formule a sus conflictos, es un elemento que debe considerar el empresario al momento de asumir el riesgo de involucrarse en ella, pues el desarrollo fluido o no de la misma dependerá de esos supuestos.

En relación con la solución judicial de los conflictos es importante recordar que el ordenamiento jurídico colombiano se enmarca en un modelo complejo en torno a fuentes del derecho y, en consecuencia, sus métodos de interpretación, toda vez que existe una mixtura - marcada con mayor precisión a raíz de los pronunciamientos de la Corte Constitucional- de teorías que alimentan las perspectivas de la validez y la eficacia.

Pese a los intentos del TAS por atender a ese modelo complejo de fuentes y métodos de interpretación descritos, existen casos en los que la labor interpretativa hace mayor acento en la ley y la jurisprudencia como fuentes del derecho, se involucra de manera progresiva al contrato, la Constitución y otras fuentes.

Lo anterior en la medida en que la labor interpretativa del TAS en el periodo 2008 - 2009, desplegada con el ánimo de dar solución a los conflictos contractuales sometidos a su conocimiento tuvo un acento marcado en el uso de la ley y la jurisprudencia como principales fuentes del derecho, con algunas excepciones en los conflictos en torno a la nulidad, en los cuales el sistema de fuentes se integra de manera más compleja por la Constitución, el contrato y otras fuentes adicionales.

De acuerdo a la forma de integración del sistema de fuentes, los métodos de interpretación más utilizados por el TAS, en ejercicio de su función de declarativa del derecho, son: el exegético con su especificación de análisis gramatical y semántico, además de la aplicación de las reglas de interpretación contractual consagradas en 
el Código Civil; el lógico a través de argumentos lógicos como el de contrariedad y reducción al absurdo; el sistemático a partir de la integración de la institución sea por la división del ordenamiento jurídico, el desglose de un precepto constitucional o la integración del contexto; el finalista en función de la finalidad de una norma superior o de la ley; y el histórico a partir de la revisión de la evolución normativa de la norma.

En este sentido la función del TAS siempre fue declarativa del derecho vigente y se caracterizó, en la mayoría de los casos, por hacer un análisis adjetivo previo al análisis de fondo. Este análisis adjetivo en ocasiones, especialmente cuando a conflictos por incumplimiento del contrato se refiere, impidió al TAS ahondar en el estudio de fondo demandado.

Derivada de la función declarativa, el TAS se caracterizó en todos sus fallos por hacer uso de una racionabilidad limitada, entendida por el uso de insumos jurídicos propios del ordenamiento jurídico, por lo que su función no se desbordó del deber de aplicar el derecho. Es desarrollo de esta racionalidad, la solución a conflictos en torno a la nulidad y a la ocurrencia de hechos imprevisibles y el rompimiento de equilibrio económico, el TAS intentó hacer una corrección material a partir del uso de argumentos de orden constitucional y en ocasiones fue consecuencialista al considerar aspectos económicos, políticos y sociales, entre otros, para favorecer los intereses de la administración o de terceros.

En el punto de discrecionalidad, el TAS se caracterizó por interpretar las normas aplicables y decidir conforme a la que más se adecuara al conflicto sometido a su conocimiento. De allí que a pesar de las decisiones desfavorables a los intereses de la persona de derecho privado, puede la misma justificarse en los casos sobre nulidad, ocurrencia de hechos imprevisibles y rompimiento del equilibrio económico y existencia del contrato, pues en los casos de incumplimiento el análisis adjetivo, que impidió hacer estudio de fondo del conflicto, no se encuentran fundamentos sustanciales de la negación de las pretensiones y en los casos sobre liquidación judicial del contrato, el TAS accedió a las pretensiones.

Finalmente, en términos de la pureza del método, resta decir que la decisión judicial adoptada por el TAS, con algunas excepciones ya mencionadas, se justificó a partir de los insumos o fuentes del derecho y el ejercicio interpretativo de los mismos, dando coherencia a las decisiones.

Todas las discusiones e investigaciones en torno a la solución judicial de los conflictos se justifican porque

nos interesamos en el derecho, no sólo porque lo utilizamos para nuestros propósitos, egoístas o nobles, sino porque el derecho es nuestra institución social más estructurada y reveladora. Si comprendemos mejor la naturaleza de nuestro argumento legal, conocemos mejor qué clase de personas somos. (Dworkin, 2008, pp. 15 - 23) 


\section{REFERENCIAS}

Asamblea Nacional Constituyente. (1991). Constitución Política de Colombia, Bogotá.

Blanco Zúñiga, Gilberto. (2007). Sistema de Fuentes en el ordenamiento jurídico colombiano. Barranquilla (Colombia): Ediciones UNINORTE. 318 p. ISBN. 978-958-8252-51-3.

Bobbio, Norberto. (1997). Teoría general del derecho. Santafé de Bogotá: Editorial Temis. p, 20.

David, René. (1973). Los grandes sistemas jurídicos contemporáneos, Madrid: Aguilar, p, 25.

Dávila Vinueza, Luis Guillermo. (2003). Régimen Jurídico de la Contratación Estatal: aproximación crítica a la Ley 80 de 1993. 2da. Ed. Legis. Bogotá D. C., 890 p.

Delgado Gamboa, Rodolfo y Súarez Manrique, Wilson Yesid. (2010). Los principales factores del sistema de fuentes En Revista IUSTITIA, No. 8 Bucaramanga: Universidad Santo Tomás, Enero - Diciembre. ISSN 1692-9403

Delgado Gamboa, Rodolfo. (2010). Autonomía Privada: Contratos en el Estado Social de Derecho en Memorias del $2^{\circ}$ Congreso Internacional de Derecho Empresarial y Contractual. Bucaramanga: Universidad Santo Tomás, Octubre. Pp. 58 - 95. ISBN: 978-958-8477-21-3.

Dworkin, Ronald. (2008). El imperio de la Justicia; Barcelona, España: Gedisa S. A.

Gómez, Francisco. (2004). Constitución Política de Colombia Anotada; Bogotá, Colombia: Leyer.

Lamprea Rodríguez, Pedro A. (2007). Contratos Estatales. Editorial Temis S. A. Bogotá D. C., 700 p.

Legis Editores, (2008). Estatuto General de la Contratación de la Administración Pública. 4ª . Ed. Legis, Bogotá D. C., 724 p.

Mier, Patricia. (Mayo de 2004). El régimen jurídico del contrato estatal en Revista de derecho público (No. 17), Bogotá D.C.: Facultad de Derecho (Universidad de Los Andes), pp. 59 - 76.

Montes, Susana. (2002). La solución de controversias contractuales por la vía arbitral en Revista de derecho público (No. 14), Bogotá D.C.: Facultad de Derecho (Universidad de Los Andes). pp. 135 - 142. Recuperado el 21 de mayo de 2010 de http:// derechopublico.uniandes.edu.co/pdfs/R14_A9.pdf

Ramírez, Elizabeth. (2001). La investigación Socio-Jurídica. Bogotá D. C, Colombia: Ediciones Doctrina y Ley Ltda. 392 p.

República De Colombia. Código Civil Colombiano.

. (2011). Código Contencioso Administrativo -Comentado-. 25ª Ed. Bogotá: Legis.

- (1993). Ley 80. Por la cual se expide el Estatuto General de Contratación de la Administración Pública. 
Reyes, Angélica María. (2010). Cláusulas Excepcionales y equilibrio económico: protecciones en la ejecución del contrato con la administración pública. Memorias del $2^{\circ}$ Congreso Internacional de Derecho Empresarial y Contractual, Universidad Santo Tomás Bucaramanga. p. 391 - 411.

Reyes, Angélica María. (2011). Límites a la autonomía de la voluntad del empresario contratista colaborador de la administración pública. Tendencias actuales del derecho privado: Una mirada desde la investigación, Universidad Antonio Nariño Bogotá. Pp. 263 - 280.

Rico, L. (2009). Teoría general y práctica de la contratación estatal (Sexta edición ed.). Bogotá D. C., Colombia: Leyer.

Rocha, Cesáreo. (2006). Manual de introducción la Derecho, Bogotá D. C., Colombia: Editorial Universidad del Rosario. 325 p. ISBN 958 - 2898 - 10 - 5.

Tafur, Álvaro. (2004). Código Civil Colombiano Anotado. Bogotá D.C; Colombia: Leyer.

Tribunal Administrativo De Santander. Proceso 2002 - 1576, Sentencia del 27 de Agosto de 2009. Mg. Ponente. Julio Edison Ramos Salazar.

Proceso 1998 - 1586, Sentencia del 9 de Julio de 2009. Mg. Ponente. Solange Blanco Villamizar.

Proceso 1998 - 1623, Sentencia del 28 de Mayo de 2009. Mg. Ponente. Francy del Pilar Pinilla Pedraza.

. Proceso 1998 - 810, Sentencia del 21 de Agosto de 2009. Mg. Ponente. Milcíades Rodríguez Quintero.

Proceso 1999 - 123, Sentencia del 29 de Agosto de 2008. Mg. Ponente. Francy del Pilar Pinilla Pedraza.

Proceso 1999 - 1329, Sentencia del 23 de Mayo de 2008. Mg. Ponente. Rafael Gutiérrez Solano.

. Proceso 1999 - 846, Sentencia del 22 de Enero de 2009. Mg. Ponente. Milciades Rodríguez Quintero.

. Proceso 2000 - 1514, Sentencia del 31 de Julio de 2008. Mg. Ponente. Milciades Rodríguez Quintero.

Proceso 2000 - 1815, Sentencia del 10 de Diciembre de 2009. Mg. Ponente. Francy del Pilar Pinilla Pedraza.

. Proceso 2000 - 2535, Sentencia del 13 de Agosto de 2009. Mg. Ponente. Francy del Pilar Pinilla Pedraza.

. Proceso 2000 - 2608, Sentencia del 19 de Febrero de 2009. Mg. Ponente. Solange Blanco Villamizar.

Proceso 2000 - 2920, Sentencia del 4 de Septiembre de 2008. Mg. Ponente. Solange Blanco Villamizar.

. Proceso 2000 - 891, Sentencia del 8 de Octubre de 2009. Mg. Ponente.

Solange Blanco Villamizar. 
Proceso 2002 - 350, Sentencia del 11 de Junio de 2009. Mg. Ponente. Solange Blanco Villamizar.

. Proceso 2004 - 382, Sentencia del 9 de Julio de 2009. Mg. Ponente. Francy del Pilar Pinilla Pedraza.

. Proceso 2005 - 1043, Sentencia del 25 de Julio de 2008. Mg. Ponente. Rafael Gutiérrez Solano.

Zambrano, César. (2002). Solución de las controversias contractuales mediante el sistema judicial. Problemas y recomendaciones en Revista de derecho público (No. 14), Bogotá D.C.: Facultad de Derecho (Universidad de Los Andes). Pp. 119 - 124. Recuperado el 21 de mayo de 2010 de http://derechopublico.uniandes. edu.co/pdfs/ R14_A7.pdf 